\title{
Estrogen Attenuates Ischemic Oxidative Damage via an Estrogen Receptor $\alpha$-Mediated Inhibition of NADPH Oxidase Activation
}

\author{
Quan-Guang Zhang, ${ }^{1 \star}$ Limor Raz, ${ }^{1 \star}$ Ruimin Wang, ${ }^{2 \star}$ Dong Han, ${ }^{1}$ Liesl De Sevilla, ${ }^{1}$ Fang Yang, ${ }^{2}$ Ratna K. Vadlamudi, ${ }^{3}$ \\ and Darrell W. Brann ${ }^{1}$ \\ 1Developmental Neurobiology Program, Institute of Molecular Medicine and Genetics, and Department of Neurology, Medical College of Georgia, Augusta, \\ Georgia 30912, ${ }^{2}$ Research Center for Molecular Biology, North China Coal Medical University, Tangshan 063000, China, and ${ }^{3}$ Department of Obstetrics and \\ Gynecology, University of Texas Health Science Center at San Antonio, San Antonio, Texas 78229
}

The goal of this study was to elucidate the mechanisms of $17 \beta$-estradiol $\left(\mathrm{E}_{2}\right)$ antioxidant and neuroprotective actions in stroke. The results reveal a novel extranuclear receptor-mediated antioxidant mechanism for $\mathrm{E}_{2}$ during stroke, as well as a hypersensitivity of the CA3/CA4 region to ischemic injury after prolonged hypoestrogenicity. $\mathrm{E}_{2}$ neuroprotection was shown to involve a profound attenuation of NADPH oxidase activation and superoxide production in hippocampal CA1 pyramidal neurons after stroke, an effect mediated by extranuclear estrogen receptor $\alpha(\mathrm{ER} \alpha)$-mediated nongenomic signaling, involving Akt activation and subsequent phosphorylation/ inactivation of Rac1, a factor critical for activation of NOX2 NADPH oxidase. Intriguingly, $\mathrm{E}_{2}$ nongenomic signaling, antioxidant action, and neuroprotection in the CA1 region were lost after long-term $\mathrm{E}_{2}$ deprivation, and this loss was tissue specific because the uterus remained responsive to $\mathrm{E}_{2}$. Correspondingly, a remarkable loss of $\mathrm{ER} \alpha$, but not $\mathrm{ER} \beta$, was observed in the CA1 after long-term $\mathrm{E}_{2}$ deprivation, with no change observed in the uterus. As a whole, the study reveals a novel, membrane-mediated antioxidant mechanism in neurons by $\mathrm{E}_{2}$ provides support and mechanistic insights for a "critical period" of $\mathrm{E}_{2}$ replacement in the hippocampus and demonstrates a heretofore unknown hypersensitivity of the CA3/CA4 to ischemic injury after prolonged hypoestrogenicity.

\section{Introduction}

The steroid hormone $17 \beta$-estradiol $\left(\mathrm{E}_{2}\right)$ has been implicated to be neuroprotective in a variety of neurodegenerative disorders, such as stroke, Parkinson's disease, and Alzheimer's disease (Simpkins et al., 1997; Sherwin, 2003; Miller et al., 2005; Brann et al., 2007; Henderson, 2008; Morissette et al., 2008), although the mechanism for such broad-based neuroprotection remains unclear. With respect to stroke, $\mathrm{E}_{2}$ has been shown to be neuroprotective in rodent models of both focal and global cerebral ischemia (Simpkins et al., 1997; Toung et al., 1998; Miller et al., 2005; Brann et al., 2007; Zhang et al., 2008). Furthermore, it is well known that women are "protected" against stroke relative to men, at least until menopause (Roquer et al., 2003; Murphy et al., 2004; Niewada et al., 2005), and that after menopause, women reportedly have a worse stroke outcome compared with males (Di Carlo et al., 2003; Niewada et al., 2005). $\mathrm{E}_{2}$ has also been implicated to act in the hippocampus to enhance synaptic plasticity and cognitive function (Sandstrom and Williams, 2001; Li

Received July 23, 2009; revised Aug. 21, 2009; accepted Sept. 15, 2009.

This research was supported by National Institute of Neurological Diseases and Stroke/National Institutes of Health Research Grant NS050730.

${ }^{*} Q$. -G.Z., L.R., and R.W. contributed equally to this work and should be considered first coauthors.

Correspondence should be addressed to Dr. Darrell W. Brann, Developmental Neurobiology Program, Institute of Molecular Medicine and Genetics, 1120 Fifteenth Street, Medical College of Georgia, Augusta, GA 30912. E-mail: dbrann@mcg.edu.

DOI:10.1523/JNEUROSCI.3574-09.2009

Copyright $\odot 2009$ Society for Neuroscience $\quad$ 0270-6474/09/2913823-14\$15.00/0 et al., 2004; Sherwin, 2007b; Spencer et al., 2008). Interestingly, long-term ovariectomy (surgical menopause) has been shown to be correlated with an increased risk of cognitive decline and dementia in humans (Rocca et al., 2007, 2008; Shuster et al., 2008).

In contrast to the beneficial effects reported for estrogen in animal and observational studies, the Women's Health Initiative (WHI) study failed to find a beneficial cardiovascular/neural effect of hormone replacement therapy (HRT) and in fact found an increased risk for stroke and dementia in postmenopausal women receiving HRT (Shumaker et al., 2003; WassertheilSmoller et al., 2003; Anderson et al., 2004; Espeland et al., 2004). However, it should be pointed out that the average age of subjects in the WHI study was 63-65 years, which is far past the menopause. This has led Sherwin and others (Maki, 2006; Sherwin, 2007a; Sherwin and Henry, 2008) to suggest that there exists a "critical period" for estrogen beneficial effect in the brain, in which estrogen replacement may need to be initiated at perimenopause to observe its beneficial effects on neuroprotection and cognition. In potential support of this hypothesis, rodent studies have shown that neuroprotection of the cerebral cortex by $E_{2}$ is lost in long-term $\mathrm{E}_{2}$-deprived animals after middle cerebral artery occlusion (MCAO) (Suzuki et al., 2007).

Several important questions have arisen out of this body of work: (1) how does $E_{2}$ exert a broad-based neuroprotective effect in different neurodegenerative disorders, including stroke, (2) is there a critical period for $\mathrm{E}_{2}$ protection of the hippocampus CA1 region, and (3) what is the mechanism underlying such a critical 
period and is it tissue specific? The current study sheds light on these important questions by demonstrating a novel, extranuclear receptor-mediated antioxidant mechanism of $E_{2}$ in hippocampal CA1 neurons to suppress ischemic activation of NOX2 NADPH oxidase, a membrane enzyme that generates the highly reactive free radical, superoxide $\left(\mathrm{O}_{2}^{-}\right)$(Bedard and Krause, 2007). NOX2 NADPH oxidase is highly localized in the hippocampal CA1 region (Serrano et al., 2003), and its activation is dependent on forming an active complex with several cytosolic factors (p47phox, p67phox, and p40phox) and activated Rac1, which translocate to the membrane after activation (Serrano et al., 2003; Bedard and Krause, 2007). The current study also demonstrates that a critical period exists for the antioxidant and neuroprotective effects of $\mathrm{E}_{2}$ in the hippocampus $\mathrm{CA} 1$ region, which are tissue specific, because the uterus remains sensitive to $\mathrm{E}_{2}$ after a period of prolonged hypoestrogenicity. Finally, the hippocampal CA3/ CA4 region also showed a marked hypersensitivity to ischemic damage after prolonged hypoestrogenicity, which may explain the increased risk of cognitive decline and dementia observed in women after natural or surgical menopause.

\section{Materials and Methods}

Global cerebral ischemia. Adult (3-month-old) Sprague Dawley female rats were bilaterally ovariectomized. Placebo (Pla) or $\mathrm{E}_{2}$ Alzet minipumps (0.025 mg; $14-21 \mathrm{~d}$ release) were implanted subcutaneously in the upper mid-back region under the skin at the time of ovariectomy [immediate (Imm)] and global cerebral ischemia (GCI) performed 1 week later. In some animals, long-term $\mathrm{E}_{2}$ deprivation was performed in which the animals were ovariectomized and, 10 weeks later $(10 \mathrm{~W})$, placebo or $\mathrm{E}_{2}$ minipumps were implanted, and 1 week later GCI was performed (supplemental Fig. 1, available at www.jneurosci.org as supplemental material). The dose of $E_{2}$ used produces serum $E_{2}$ levels of $\sim 10 \mathrm{pg} / \mathrm{ml}$, which represents physiological low diestrus I levels of $\mathrm{E}_{2}$ (Zhang et al., 2008). For GCI, all animals (except sham control) underwent four-vessel occlusion GCI performed as described previously (Pulsinelli and Brierley, 1979; Pulsinelli and Buchan, 1988; Zhang et al., 2006a, 2008). Briefly, $24 \mathrm{~h}$ after electrocautery of the vertebral arteries, the common carotid arteries (CCAs) were occluded with aneurysm clips to induce $10 \mathrm{~min}$ forebrain ischemia. Animals that lost their righting reflex within $30 \mathrm{~s}$ and whose pupils were dilated and unresponsive to light during GCI were selected for the experiments, because this indicates successful GCI. The clips were then removed, and the blood flow through the arteries was confirmed before the wound was sutured. Rectal temperature was maintained at $36.5-37.5^{\circ} \mathrm{C}$ throughout the experiment with a thermal blanket. The animals of the sham group underwent identical procedures except that the CCAs were simply exposed but not occluded.

Histology analysis. Histological examination of the ischemic brain was performed by neuronal-specific nuclear protein (NeuN) and FluoroJade B as described previously by our laboratory (Zhang et al., 2008). Briefly, after perfusion with $0.9 \%$ saline followed by $4 \%$ paraformaldehyde (PFA) in $0.1 \mathrm{~m}$ phosphate buffer, the brains were postfixed, cryoprotected with $30 \%$ sucrose until they sank, and frozen sectioned (20 $\mu \mathrm{m})$ in the coronal plane of the dorsal hippocampus $(\sim 2.5-4.5 \mathrm{~mm}$ posterior from bregma). Every fifth section was collected and used for staining. Staining for NeuN and Fluoro-Jade B was performed using a mouse anti-NeuN monoclonal antibody (1:500; Millipore Bioscience Research Reagents) and Fluoro-Jade B (AG310; Millipore Bioscience Research Reagents) as described in detail previously by our laboratory (Zhang et al., 2008). Images were captured on an LSM510 Meta confocal laser microscope (Carl Zeiss) as described previously by our laboratory (Wakade et al., 2008). Cells that positively stained with NeuN and negatively stained with Fluoro-Jade B were identified as "surviving neurons"; in contrast, double-stained yellow-colored cells represent CA1 neurons undergoing degeneration.

Terminal deoxynucleotidyl transferase-mediated biotinylated UTP nick end (TUNEL) staining was performed on the free-floating coronal sections using the In Situ Cell Death Detection kit (Roche) following the instructions of the manufacturer. Briefly, after washing with $0.1 \%$ PBSTriton X-100, the slides were permeabilized with $10 \mu \mathrm{g} / \mathrm{ml}$ proteinase $\mathrm{K}$ in $10 \mathrm{~mm}$ Tris/ $\mathrm{HCl}, \mathrm{pH} \mathrm{7.4,} \mathrm{for} 15 \mathrm{~min}$ and incubated with TUNEL reaction mixture including enzyme solution (terminal deoxynucleotidyl transferase) and tetramethylrhodamine-labeled TUNEL-positive nucleotides in a humidified chamber for $1 \mathrm{~h}$ at $37^{\circ} \mathrm{C}$. Slides for negative control were incubated with the label solution without terminal transferase for TUNEL. Samples were analyzed with a LSM510 Meta confocal microscope. For quantitative analyses, the number of surviving neurons and TUNEL-positive cells per $250 \mu \mathrm{m}$ length of medial CA1 pyramidal cell layer were counted bilaterally in four to five sections per animal to provide a single value for each animal. A mean \pm SE was calculated from the data in each group ( $n=6-8$ animals), and statistical analysis was performed as described below.

$D A B$ staining. For DAB staining, sections were incubated with $10 \%$ normal goat/horse serum in PBS containing $0.1 \%$ Triton X-100 and $0.3 \%$ $\mathrm{H}_{2} \mathrm{O}_{2}$ for $1 \mathrm{~h}$ at room temperature to block nonspecific surfaces. Sections were then incubated with the primary antibodies overnight at $4^{\circ} \mathrm{C}$ in PBS containing $0.1 \%$ Triton $\mathrm{X}-100$. The antibodies used were as follows: mouse anti-4-hydroxy-2-nonenal (4-HNE) (1:500; Genox), mouse anti8-hydroxy-2'-deoxyguanosine (8-OHdG) (1:100; Genox), polyclonal rabbit anti-P47 (1:100; Cell Signaling Technology), and anti-NOX2/ gp91phox (1:1000; Abcam). Afterward, sections were washed with the same buffer, followed by incubation with secondary biotinylated horse anti-mouse or goat anti-rabbit antibodies (Vector Laboratories) at a dilution of 1:200 in PBS containing 0.1\% Triton X-100 for $1 \mathrm{~h}$ at room temperature. Sections were then washed, followed by incubation with $\mathrm{ABC}$ reagents for $1 \mathrm{~h}$ at room temperature in the same buffer. Sections were rinsed in the same buffer and incubated with DAB reagent according to the instructions of the manufacturer (Vector Laboratories) for 2-10 min. After DAB incubation, sections were washed briefly with distilled water and dehydrated in graded alcohols, cleared in xylene, and mounted using xylene-based mounting medium. Images were captured on an Axiophot-2 visible/fluorescence microscope using an AxioVision4Ac software system (Carl Zeiss).

Double/triple immunofluorescence staining. Coronal sections were incubated with $10 \%$ normal donkey serum for $1 \mathrm{~h}$ at room temperature in PBS containing $0.1 \%$ Triton X-100, followed by incubation with appropriate primary antibodies overnight at $4^{\circ} \mathrm{C}$ in the same buffer. The following primary antibodies were used in different combinations: antiNeuN (1:500; Millipore Bioscience Research Reagents), anti-phosphoH2A.X (1:100; Cell Signaling Technology), anti-p47phox, anti-GFAP, and anti-p-Akt (1:50; Santa Cruz Biotechnology), and anti-NOX2 (1: 1000; Abcam). After primary antibody incubation, sections were washed for four times for $10 \mathrm{~min}$ at room temperature, followed by incubation with Alexa-Fluor594/647 donkey anti-mouse/rabbit, Alexa-Fluor488/ 594 donkey anti-rabbit/mouse, or Alexa-Fluor488/594 donkey anti-goat secondary antibody (1:500; Invitrogen) for $1 \mathrm{~h}$ at room temperature. Sections were then washed with PBS containing $0.1 \%$ Triton X-100 four times for $10 \mathrm{~min}$, followed by three 5-min washes with PBS and briefly with water, and then mounted with water-based mounting medium containing anti-fading agents (Biomeda-Fisher Scientific). A simultaneous examination of negative controls (omission of primary antibody) confirmed the absence of nonspecific immunofluorescent staining, crossimmunostaining, or fluorescence bleed-through.

Confocal microscopy and image analysis. All the double- and triplelabeled images were captured on an LSM510 Meta confocal laser microscope (Carl Zeiss) using either a $5 \times$ or $40 \times$ oil-immersion Neofluor objective (1.3 numerical aperture) with the image size set at $1024 \times 1024$ pixels. The following excitation/emission laser filter settings were used for various chromophores: an argon/2 laser was used for Alexa-Fluor488, with excitation maximum at $490 \mathrm{~nm}$ and emission in the range of 505$530 \mathrm{~nm}$, a helium-neon laser was used for Alexa-Fluor594 with excitation maximum at $543 \mathrm{~nm}$ and emission in the range of 568-615 nm, and a second helium-neon laser was used for Alexa-Fluor647 with excitation maximum at $633 \mathrm{~nm}$ and emission in the range of $650-800 \mathrm{~nm}$. The captured images were viewed and analyzed using LSM510 Meta imaging software.

In situ detection of superoxide production. The production of $\mathrm{O}_{2}^{-}$radicals was investigated using hydroethidine (HEt) (Invitrogen) as de- 
scribed previously by our group and others (Bindokas et al., 1996; Wakade et al., 2008). In the present study, HEt ( $1 \mathrm{mg} / \mathrm{ml}$ in $200 \mu \mathrm{l}$ of PBS) was administered intravenously $30 \mathrm{~min}$ before ischemia. Animals were anesthetized using isoflurane $3 \mathrm{~h}$ after ischemia and transcardially perfused with cold PBS and 4\% PFA. Sham non-ischemic control animals were also treated with HEt solution as $\mathrm{O}_{2}^{-}$production control. Fluorescent intensity of the oxidized HEt was measured on a confocal laser microscope using an excitation wavelength of $543 \mathrm{~nm}$, and the emission was recorded at wavelengths between 560 and $590 \mathrm{~nm}$. The images were examined using LSM 510 image software, and the optical intensity of HEt signals in each recorded medial CA1 objective field was measured with the NIH Image J analysis software (version 1.30v). The mean intensity was determined from four fields in each animal, and values (four or five rats in each group) were expressed as fold changes versus sham control.

Brain homogenates and subcellular fractionations. For brain tissue preparation, rats were killed under anesthesia at the indicated time points. Whole brains were removed, and the hippocampal CA1 and CA3/dentate gyrus (DG) regions were microdissected from both sides of the hippocampal fissure and immediately frozen in liquid nitrogen. Total protein, nuclear, cytosol, and crude membrane fractions were extracted as follows. Briefly, tissues samples were gently homogenized using a glass homogenizer in $1.2 \mathrm{ml}$ of ice-cold buffer A containing $1.5 \mathrm{ml}$ of $10 \mathrm{~mm}$ HEPES, pH 7.4, 0.5 mм MgCl $2,10 \mathrm{~mm} \mathrm{KCl,} 0.1$ mм EDTA, 0.1 mм EGTA, $50 \mathrm{~mm} \mathrm{NaF}, 5 \mathrm{~mm}$ dithiotheitol, $10 \mathrm{~mm} \beta$-phosphoglycerol, $1 \mathrm{~mm} \mathrm{Na}_{3} \mathrm{VO}_{4}, 1$ mu phenylmethylsulfonyl fluoride (PMSF), 1 mm 4-nitrophenyl phosphate, and protease inhibitor mixture (Sigma). Two hundred microliters of the above homogenates were separated and sonicated as total protein lysates. The remaining homogenates were centrifuged at $1000 \times g$ at $4^{\circ} \mathrm{C}$ for 10 min to get supernatant (S1) fractions and nuclear fractions (P1). P1 fractions were then extracted with our previously described procedure (Zhang et al., 2008) and used as a crude nuclear fraction. S1 fractions were centrifuged at $13,000 \times g$ for $20 \mathrm{~min}$ at $4^{\circ} \mathrm{C}$ (results in S2 fractions and P2 mitochondria/microsome fractions) and further centrifuged at $100,000 \times g$ for $30 \mathrm{~min}$ to obtain the cytosolic fractions (S3) and the plasma membrane-enriched fractions (P3). The pellet membranes fractions were resuspended in buffer A containing $0.1 \%$ Triton X-100 for $10 \mathrm{~s}$ by sonication. The protein concentrations were determined by the Modified Lowry Protein Assay (Pierce). All the samples were stored at $-80^{\circ} \mathrm{C}$ until use.

Immunoprecipitation and Western blotting. For immunoprecipitation (IP), the supernatant (S2) fractions (each containing $400 \mu \mathrm{g}$ of protein) were diluted fourfold with HEPES buffer containing $50 \mathrm{~mm}$ HEPES, pH7.4, $150 \mathrm{~mm} \mathrm{NaCl}, 10 \%$ glycerol, $1 \%$ Triton X-100, and $1 \mathrm{~mm}$ each of EGTA, EDTA, PMSF, and $\mathrm{Na}_{3} \mathrm{VO}_{4}$. Samples were preincubated for $1 \mathrm{~h}$ with $20 \mu \mathrm{l}$ of protein $\mathrm{A} / \mathrm{G}$ and then centrifuged to remove any protein adhered nonspecifically to the protein $A / G$. The supernatant was incubated with $5 \mu \mathrm{g}$ of proper antibodies for $4 \mathrm{~h}$ at $4^{\circ} \mathrm{C}$. After the addition of protein A/G-Sepharose, the mixture was incubated at $4^{\circ} \mathrm{C}$ for an additional $2 \mathrm{~h}$. Samples were washed three times with HEPES buffer and eluted by SDS-PAGE loading buffer and then boiled for 5 min.

Western blotting was performed as described in detail previously (Zhang et al., 2008). The antibodies used were as follows: phosphoH2A.X (1:1000; Cell Signaling Technology), $\beta$-actin (1:2000; Sigma), $\mathrm{Na}^{+} / \mathrm{K}^{+}$-ATPase (1:1000; Millipore Bioscience Research Reagents), Rac1 (1:1000; BD Biosciences Transduction Laboratories), NOX2 (1: 1000; Abcam), phospho-Rac1 ( $\mathrm{Ser}^{71}$ ) (1:1000; Cell Signaling Technology); antibodies to pan-cadherin, p47phox, p67phox, GFAP, p-Akt, Akt, phosphatidylinositol 3-kinase (PI3K)-p85, ER $\alpha$, and $\mathrm{ER} \beta$ for IP or Western blots (1:200) were from Santa Cruz Biotechnology. The membrane was then washed with TBS containing Tween 20 to remove unbound antibody, followed by incubation with Alexa-Fluor 680 goat anti-rabbit/ mouse IgG for $1-2 \mathrm{~h}$ at room temperature. Bound proteins were visualized using the Odyssey Imaging System (LI-COR Bioscience), and semiquantitative analysis of the bands was performed with NIH Image J analysis software (version 1.30v). Band densities for the indicated proteins were normalized and expressed relative to total proteins, actin, or cadherin as indicated in the figures. Normalized means were then expressed as fold changes of the corresponding value for control (sham- operated) animals. A mean \pm SE was calculated from the data from all the animals for graphical presentation and statistical comparison.

NADPH oxidase activity and superoxide production assay. NADPH oxidase activity was determined based on superoxide-induced lucigenin photoemissions. For assaying NADPH oxidase enzymatic activity, $50 \mu \mathrm{g}$ of membrane fractions were used. Enzyme assays were performed in a final volume of $1 \mathrm{ml}$ containing $50 \mathrm{~mm}$ Krebs'-Ringer's phosphate buffer, pH 7.0, 1 mм EGTA, 150 mm sucrose, 0.5 mm lucigenin, $0.1 \mathrm{~mm} \mathrm{NADPH,}$ and tissue homogenate. Enzyme reactions were initiated with the addition of NADPH. No enzymatic activity could be detected in the absence of NADPH. Photoemissions, expressed in terms of relative light units (RLU), were measured every min for $5 \mathrm{~min}$ using a luminometer. Assays were performed in the dark at room temperature with appropriate controls. The rate of NADPH consumption was monitored by measuring the means values in absorbance ( $340 \mathrm{~nm}$ ), and NADPH oxidase activity was normalized by the amount of protein and the change in optical density (OD). Activity was calculated as OD per micrograms of protein per minute.

Superoxide production was measured from the indicated supernatant (S2) fractions using a LumiMax Superoxide Anion Detection kit (Stratagene) following the protocol of the manufacturer. Briefly, $50 \mu \mathrm{g}$ of sample proteins were suspended in $100 \mu \mathrm{l}$ of superoxide anion (SOA) assay medium and then mixed with $100 \mu \mathrm{l}$ of reagent mixture containing $0.2 \mathrm{~mm}$ luminal and $0.25 \mathrm{~mm}$ enhancer in SOA assay medium. Light emissions at $30 \mathrm{~s}$ intervals were recorded by a standard luminometer. Values were standardized to the amount of protein, and photons of light counted were expressed as RLU per micrograms of protein. A mean \pm SE were calculated from the data collected in each group for graphical depiction expressed as fold changes versus sham control group. Statistically analyses of the data were performed as described below.

Rac1-GTP binding assay. Rac1 activation assays were performed using PAK1-PBD color agarose beads (Cell Biolabs). Briefly, $400 \mu \mathrm{g}$ samples were mixed with $20 \mu$ l of PAK1-PBD agarose beads and incubated for $1 \mathrm{~h}$ at $4^{\circ} \mathrm{C}$. The reaction was terminated by addition of $\mathrm{MgCl}_{2}$. The agarose beads were collected by spinning at $12,000 \times g$ for $1 \mathrm{~min}$ at $4^{\circ} \mathrm{C}$, and the supernatants were removed. Precipitated complexes were washed three times with magnesium-containing TBS buffer and boiled in sample buffer. Proteins were separated by 10\% SDS-PAGE, transferred onto nitrocellulose membrane, and detected by immunoblotting using an anti-Rac1-specific antibody.

Administration of drugs. The following compounds were bilaterally infused into the lateral ventricles (from bregma: anteroposterior, \pm 0.8 $\mathrm{mm}$; lateral, $1.5 \mathrm{~mm}$; depth, $3.5 \mathrm{~mm}$ ) $30 \mathrm{~min}$ before induction of GCI: the estrogen receptor antagonist ICI182,780 $(7 \alpha, 17 \beta$-[9-[(4,4,5,5,5-pentafluoropentyl)sulfinyl]nonyl] estra-1,3,5(10)-triene-3,17-diol) [50 $\mu \mathrm{g}$ (Tocris Bioscience), dissolved in $5 \mu \mathrm{l}$ of 50\% DMSO], gp91ds-tat, and its scrambled control peptide (Scr) (100 ng each, $5 \mu \mathrm{l}$ in saline; synthesized by AnaSpec). The Racl inhibitor NSC23766 (6-N-[2-[5-(diethylamino) pentan-2-ylamino]-6-methylpyrimidin-4-yl]-2-methylquinoline-4,6diamine chloride) $(25 \mu \mathrm{l}$ in $5 \mu \mathrm{l}$ of sterile saline), $17 \beta$-estradiol dendrimer conjugate (EDC) (10 $\mu \mathrm{M}$ in $5 \mu \mathrm{l}$ of saline), and the phosphatidylinositol ether lipid analog SH-5 ([(2R)-2-methoxy-3-octadecoxypropyl] (2,3,4trihydroxy-6-methoxycyclohexyl) hydrogen phosphate) $(25 \mu \mathrm{g}$ in $10 \%$ DMSO), a recently discovered Akt-specific inhibitor (Alexis Biochemicals).

To investigate the roles of $\operatorname{ER} \alpha$ and $\operatorname{ER} \beta$ in $\mathrm{E}_{2}$ neuroprotection, 10 nmol of end-phosphorothioated HPLC-purified antisense oligodeoxynucleotides (AS-ODNs) mixed with $5 \mu$ l of in vivo-jetPEI (Polyplus Transfection) were administrated by bilateral cerebroventricular infusion every $24 \mathrm{~h}$ for $4 \mathrm{~d}$ before GCI. The last infusion was administered 30 min before CCA occlusion. The sequences used in this study were $5^{\prime}$ CATGGTCATGGTCAG-3' for ER $\alpha$ AS-ODNs and 5' -GAATGTCATAGCTGA-3' for ER $\beta$ AS-ODNs (from Integrated DNA Technologies). The same dose of scrambled missenses (MSs) (5'-ATCGTGGATCGTGAC- $\left.3^{\prime}\right)$ was used as control. These ER antisense sequences have been well described in vivo previously by others (Liang et al., 2002; Edinger and Frye, 2007; Walf et al., 2008).

For intracerebroventricular injections, anesthetized rats were placed on a stereotaxic instrument. All drug infusions as listed above were performed using a Hamilton microsyringe at a flow rate of $1 \mu \mathrm{l} / \mathrm{min}$. After 

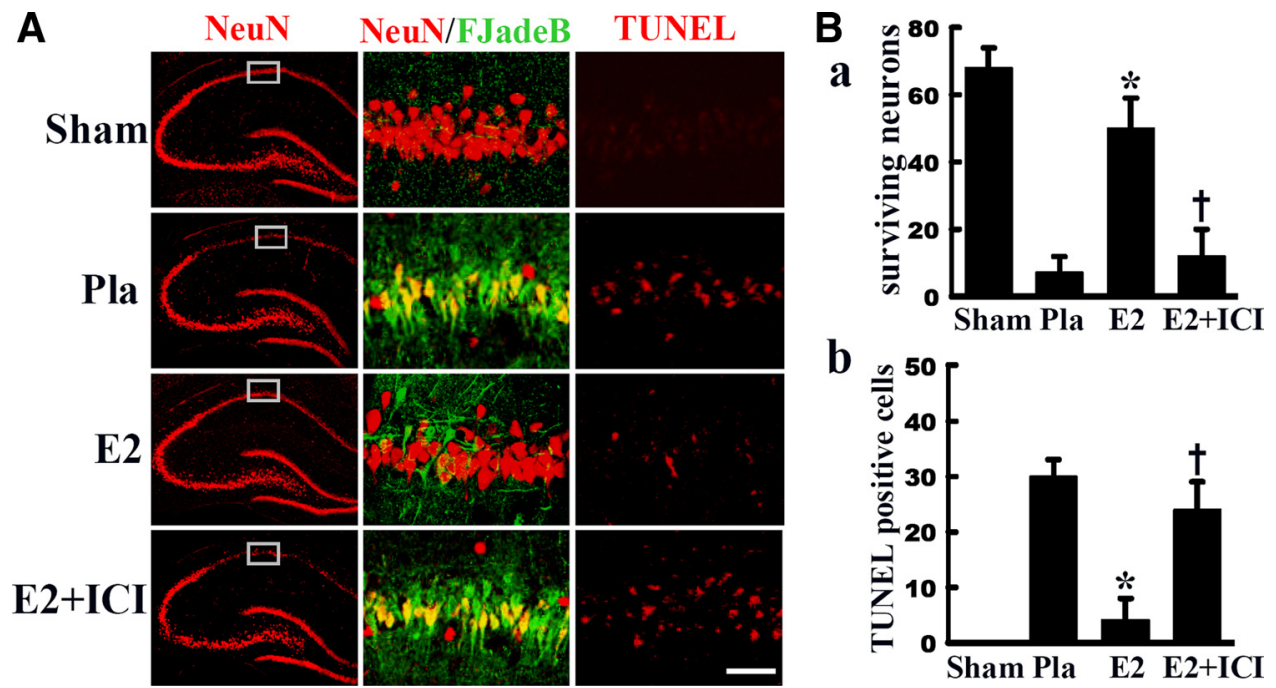

Figure 1. $E_{2}$ attenuates apoptotic neuronal cell death in hippocampal CA1 region at $7 \mathrm{~d}$ after global cerebral ischemia in an estrogen receptor-dependent manner. $A$, Hippocampal sections from sham, Pla-treated, $E_{2}$-treated, and $E_{2}$ plus the estrogen receptor antagonist ICI182,780-treated (ICI) female ovariectomized animals were double stained with NeuN (red) and Fluoro-Jade B (green) or separately stained with TUNEL (red, right column). Cells that stained positively for NeuN staining and negatively for Fluoro-Jade B staining were identified as surviving neurons. In contrast, NeuN/Fluoro-Jade B double-stained (yellow) cells represent CA1 pyramidal neurons undergoing degeneration. $B$, Quantitative summary of data (means $\pm S E ; n=6-8$ animals per group) shows the number of surviving neurons (a) or TUNEL-positive cells (b) per $250 \mu$ m length of medial CA1. Scale bar, $50 \mu \mathrm{m}$. Magnification, $40 \times .{ }^{*} p<0.01$ versus Pla group; ${ }^{\dagger} p<0.05$ versus $\mathrm{E}_{2}$ treatment group.

injection, the needle was left in situ for 5 min before the complete 2 min retraction.

Statistical analysis. Statistical analysis was performed using either oneway or two-way ANOVA analysis, followed by Student-Newman-Keuls post hoc tests to determine group differences. When groups were compared with a control group (e.g., sham), Dunnett's test was adopted for post hoc analyses after ANOVA. When only two groups were compared, a Student's $t$ test was used. Statistical significance was accepted at the $95 \%$ confidence level $(p<0.05)$. Data were expressed as mean \pm SE.

\section{Results}

$\mathrm{E}_{2}$ protects the hippocampus CA1 region from GCI-induced delayed neuronal cell death

Figure 1, $A$ and $B$, shows the neuroprotective effect of $\mathrm{E}_{2}$ on the hippocampal CA1 region after GCI. As shown in Figure $1 A$, staining for NeuN (a neuronal marker) and Fluoro-Jade B (a neuronal degeneration marker) revealed that GCI (Pla) induced a profound loss of NeuN staining with an elevation of FluoroJade B staining in the hippocampus CA1 region at $7 \mathrm{~d}$ after GCI reperfusion compared with sham control. Figure $1 B$ shows quantification of number of "surviving" neurons (cells positive for NeuN but negative for Fluoro-Jade B) in the CA1 region from all animals, which confirms that $\mathrm{E}_{2}$ exerts a robust neuroprotective effect against cerebral ischemia. Additionally, staining for TUNEL, an apoptotic marker, revealed that GCI (Pla) significantly increased TUNEL staining and the number of TUNEL-positive cells in the $\mathrm{CA} 1$ region compared with sham control, with $\mathrm{E}_{2}$ significantly attenuating this effect (Fig. $1 A, B$ ). Furthermore, $\mathrm{E}_{2}$ neuroprotection appeared to be mediated by ERs because intracerebroventricular administration of the ER antagonist ICI182,780 reversed $\mathrm{E}_{2}$ effects on NeuN and Fluoro-Jade B staining (Fig. $1 A$ ), number of surviving neurons (Fig. $1 B$ ), and number of TUNEL-positive cells in the CA1 region (Fig. $1 A, B$ ).

$\mathrm{E}_{2}$ profoundly attenuates neuronal NADPH oxidase activation, superoxide anion $\left(\mathrm{O}_{2}^{-}\right)$production, and oxidative damage in the hippocampal CA1 region after $\mathrm{GCI}$ Because reactive oxygen species (ROS) can play a major role in damaging neurons after GCI reperfusion, we next examined whether $\mathrm{E}_{2}$ exerts an antioxidant effect through regulation of NADPH oxidase activation and $\mathrm{O}_{2}^{-}$production in the hippocampal CA1 region at different times after GCI. As shown in Figure 2, $A$ and $B$, NADPH oxidase activity and $\mathrm{O}_{2}^{-}$production in the CA1 were significantly elevated in Pla versus sham control as early as 30 min after reperfusion, with peak NADPH oxidase activity and $\mathrm{O}_{2}^{-}$levels observed at $3 \mathrm{~h}$ (approximately sixfold to sevenfold increase vs sham), followed by a sharp fall from 6 to $24 \mathrm{~h}$. Intriguingly, low-dose $\mathrm{E}_{2}$ replacement profoundly attenuated NADPH oxidase activation and $\mathrm{O}_{2}^{-}$production in the hippocampal CA1 region after reperfusion (Fig. $2 \mathrm{~A}$ ), an effect blocked by the ER antagonist ICI182,780 (Fig. $2 \mathrm{~B}$ ). NADPH oxidase activation and $\mathrm{O}_{2}^{-}$production was not significantly elevated in the relatively resistant CA3/DG region after reperfusion, and $\mathrm{E}_{2}$ had no significant effect on NADPH oxidase activation and $\mathrm{O}_{2}^{-}$production in the CA3/DG (supplemental Fig. 2D, available at www.jneurosci. org as supplemental material). $\mathrm{O}_{2}^{-}$production was also assessed using the in situ oxidized HEt method, in which HEt, a marker of $\mathrm{O}_{2}^{-}$production, is selectively taken up by cells and oxidized by $\mathrm{O}_{2}^{-}$into ethidium, which provides a red fluorescence signal. As shown in Figure $2 C$, assessment of oxidized HEt signal in the CA1 region at $3 \mathrm{~h}$ after reperfusion revealed a robust induction of $\mathrm{O}_{2}^{-}$ in the Pla group compared with sham controls. $\mathrm{E}_{2}$ markedly attenuated the induction of $\mathrm{O}_{2}^{-}$in the $\mathrm{CA} 1$, an effect blocked by the ER antagonist ICI182,780. In contrast to the CA1 region, the CA3/DG region showed low oxidized HEt signal at $3 \mathrm{~h}$ after reperfusion, which is in agreement with a relative lack of NADPH oxidase activation observed in the CA3/DG (supplemental Fig. $2 C$, available at www.jneurosci.org as supplemental material). Examination of oxidative damage markers revealed that, in agreement with reduction of NADPH oxidase activity and $\mathrm{O}_{2}^{-}$by $\mathrm{E}_{2}$ after $\mathrm{GCI}, \mathrm{E}_{2}$ markedly attenuated oxidative damage in the $\mathrm{CA} 1$ region at $24 \mathrm{~h}$ after $\mathrm{GCI}$ as measured by immunostaining for 4-HNE, a marker of lipid oxidative damage, as well as 8-OHdG, a marker of DNA oxidative damage (Fig. 2D). Additionally, $48 \mathrm{~h}$ after reperfusion, the Pla group displayed a dramatic increase in the CA1 region of phosphorylation of the histone protein $\mathrm{H}_{2} \mathrm{AX}^{\text {ser139}}$, another well known marker of DNA damage in cells 

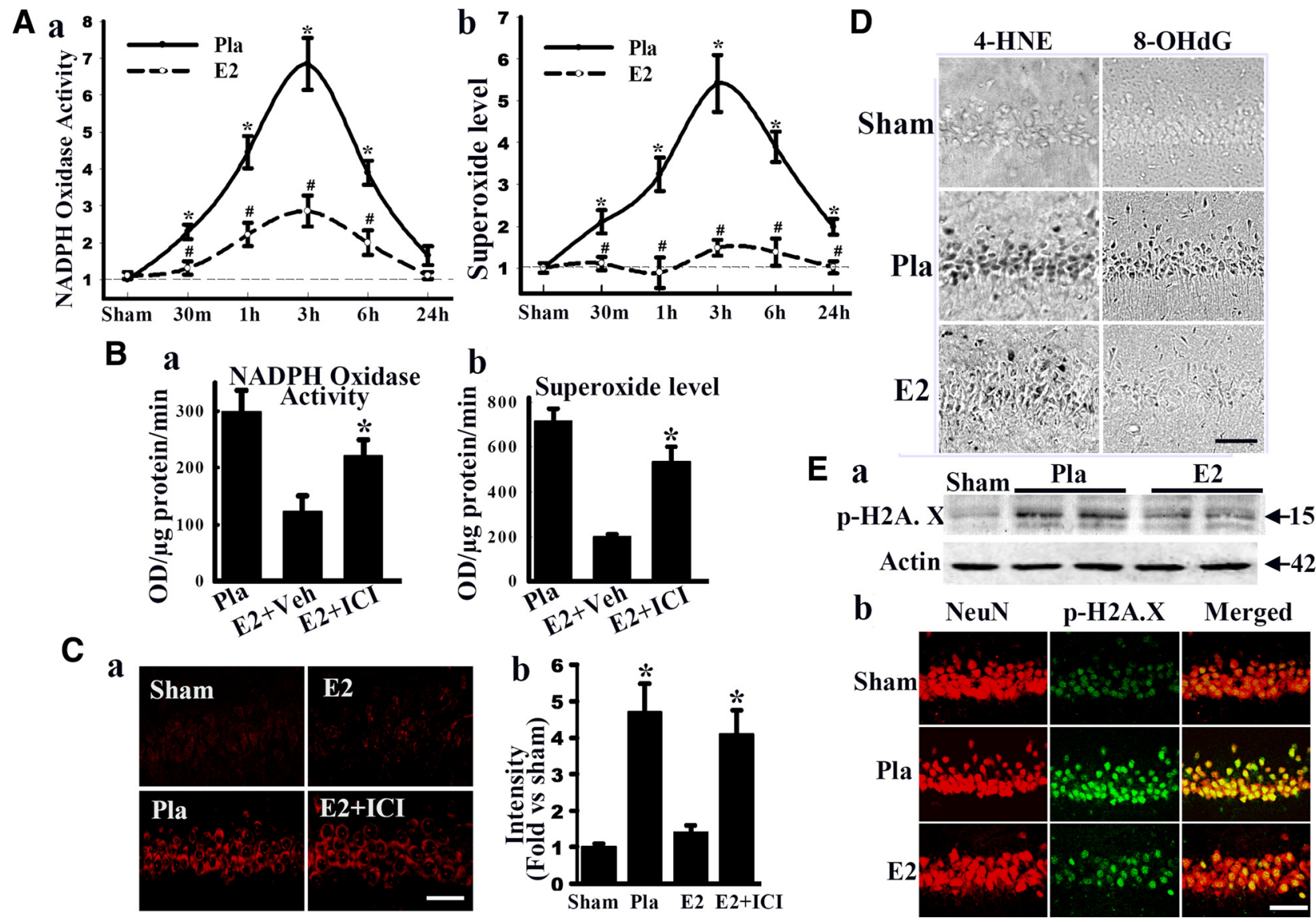

Figure 2. $E_{2}$ attenuates NADPH oxidase activity, superoxide production, and oxidative damage in hippocampal CA1 after global cerebral ischemia. $\boldsymbol{A}$, Time course of NADPH oxidase activity ( $\boldsymbol{a}$ ) and superoxide production $(\boldsymbol{b})$ in hippocampal $C A 1$ region from sham, Pla-treated, and $E_{2}$-treated rats. Values are means $\pm S E$ of four or five rats in each group and expressed as fold changed versus sham + Pla group. ${ }^{*} p<0.05$ versus sham; ${ }^{*} p<0.05$ versus Pla at the same time point. There was no difference between Pla + sham and $E_{2}+$ sham groups. $B$, Effects of ICI182,780 (ICI) on NADPH oxidase activity $(\boldsymbol{a})$ and superoxide production $(\boldsymbol{b})$ in CA1 at $3 \mathrm{~h}$ after reperfusion. ${ }^{*} p<0.05$ versus vehicle group. $\boldsymbol{C}$, Representative pictures of oxidized HEt staining taken from medial CA1 region $3 \mathrm{~h}$ after reperfusion. Strong oxidized $\mathrm{HEt}$ staining was detected in Pla-treated and $\mathrm{E}_{2}+\mathrm{ICl} 182,780$-treated brains after ischemia, whereas weak oxidized $\mathrm{HEt}$ signals were detected in sham and $\mathrm{E}_{2}$ groups $(\boldsymbol{a})$. $\mathrm{E}_{2}$ significantly attenuated superoxide generation compared with Pla, which was reversed by $\mathrm{ICl} 182,780(\boldsymbol{b}) .{ }^{*} p<0.01$ versus sham and $\mathrm{E}_{2}$. $\boldsymbol{D}$, Effect of $\mathrm{E}_{2}$ on oxidative damage markers for lipid peroxidation (4-HNE) and DNA damage (8-OHdG) $1 \mathrm{~d}$ after ischemia. Note that $\mathrm{E}_{2}$ strongly decreased 4-HNE and 8-OHdG staining. $E_{2} \mathrm{E}_{2}$ markedly decreases levels of p-H2A.X in hippocampal CA1 neurons at $2 \mathrm{~d}$ after reperfusion as determined by Western blot analysis $(\boldsymbol{a})$ and confocal immunohistochemical analysis $(\boldsymbol{b})$. Scale bars, $50 \mu \mathrm{m}$. Magnification, $40 \times$.

(Fig. $2 E a, E b)$, and this effect was almost completely prevented by $\mathrm{E}_{2}$ treatment.

NOX2 is highly expressed in hippocampal CA1 neurons and inhibition of NADPH oxidase activation attenuates $\mathrm{O}_{2}^{-}$ production and neuronal cell death after GCI

The NOX2 isoform is a major isoform of NADPH oxidase and has been shown to be highly expressed in many brain regions, including the hippocampus (Serrano et al., 2003). We thus examined whether NOX2 is localized in neurons or astrocytes in the hippocampal CA1 region after GCI. Triple immunostaining in the CA1 region at $3 \mathrm{~h}$ after GCI in Pla animals for the neuronal marker NeuN, NOX2, and the glia marker GFAP revealed that NOX2 is predominantly localized in neurons and is found in the membrane and cytoplasmic compartments (Fig. 3A). p47phox, which forms a complex with NOX2 leading to NADPH oxidase activation, was shown to also exhibit a predominant neuronal localization. Examination of the CA3/DG region revealed that it possessed extremely weak immunostaining for NOX2 and p47phox compared with the CA1 region, potentially explaining its relative resistance to ischemic damage (supplemental Fig. $2 A, B$, available at www.jneurosci.org as supplemental material). To determine whether NADPH oxidase plays a major role in $\mathrm{O}_{2}^{-}$ production and oxidative damage in the CA1 after GCI, we used the NADPH oxidase competitive antagonist gp91ds-tat, which is a 9 aa peptide sequence of the p47Phox docking site on NOX2 and prevents $\mathrm{p} 47$ phox from forming a complex with NOX2 (Rey et al., 2001). Figure $3 B$ shows that gp91ds-tat administration abolished the enhanced membrane localization of $\mathrm{p} 47 \mathrm{phox}$ in $\mathrm{Pla}$ animals observed at $3 \mathrm{~h}$ after reperfusion. In contrast, Scr had no effect on membrane $\mathrm{p} 47$ phox levels. Co-IP studies revealed that NOX2-p47phox complex formation was markedly increased in Pla animals and Scr-treated controls compared with sham controls and that gp91ds-tat treatment significantly attenuated the NOX2-p47phox complex formation, thus demonstrating its effectiveness in blocking p47phox-NOX2 complex formation. We next examined gp91ds-tat effect on NADPH oxidase activation and $\mathrm{O}_{2}^{-}$production after GCI. As shown in Figure 3C, gp91dstat, but not Scr, markedly attenuated the enhanced NADPH oxidase activation and $\mathrm{O}_{2}^{-}$production in the $\mathrm{CA} 1$ region at $3 \mathrm{~h}$ after reperfusion. gp91ds-tat also significantly increased the number of surviving neurons in the CA1 region at $7 \mathrm{~d}$ after GCI compared with Pla or the scrambled peptide control-treated animals (Fig. $3 D$ ), suggesting that activation of neuronal NADPH oxidase and enhanced $\mathrm{O}_{2}^{-}$production plays an important role in inducing neuronal death in the hippocampal CA1 region after GCI. 
A
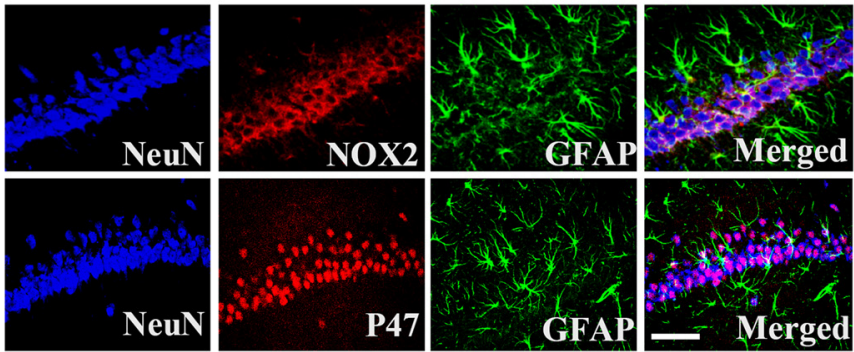

B

$\mathbf{a}$

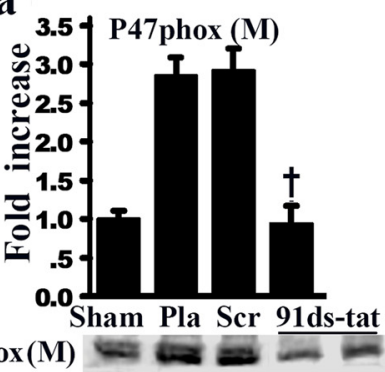

P47phox(M)

Cadherin
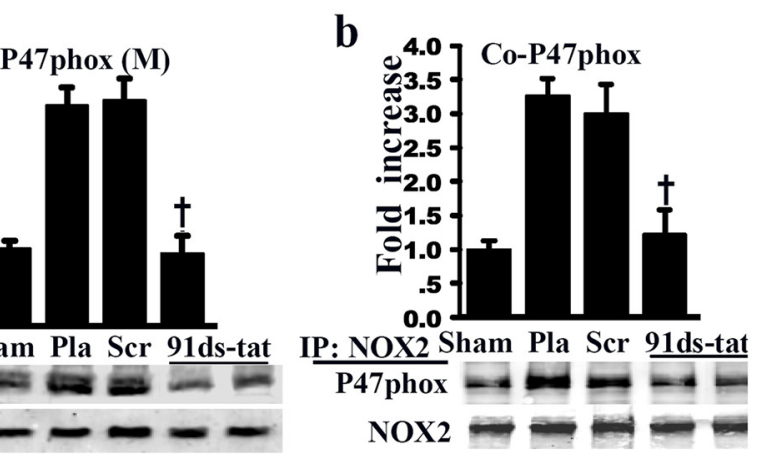
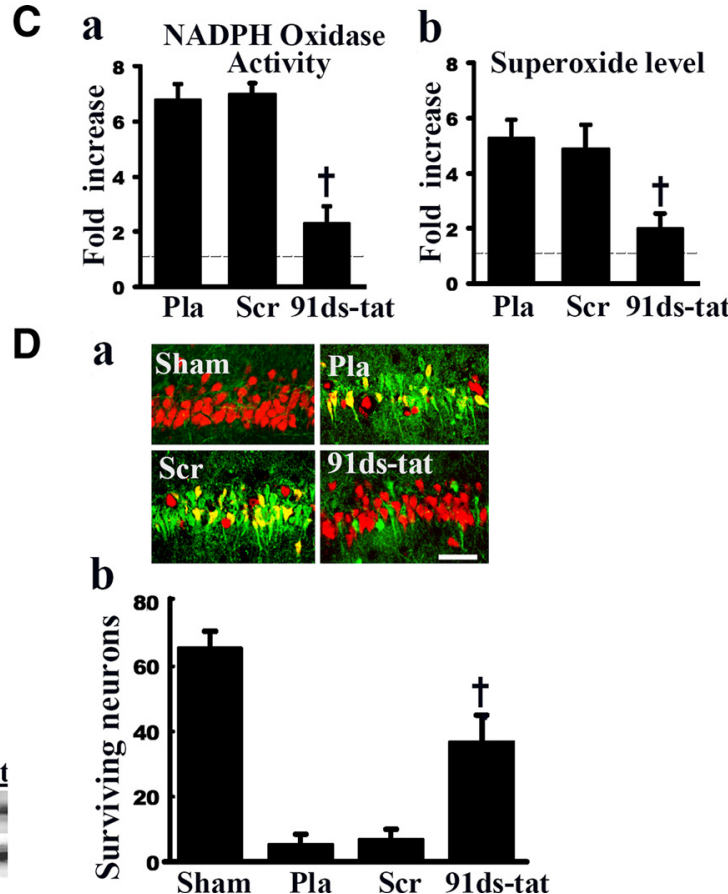

Figure 3. Critical role NOX2-containing NADPH oxidase in superoxide production and ischemic neuronal damage in hippocampal CA1. A, Confocal images show colocalization of NADPH oxidase isoforms N0X2 and p47phox with neuronal marker NeuN but not with astrocytic marker GFAP in hippocampus CA1 region at $3 \mathrm{~h}$ after reperfusion. B, Western blots using anti-p47phox (P47) and anti-cadherin antibodies on the indicated samples show membrane (M) translocation of p47phox induced by ischemia and the inhibition by the competitive N0X2 inhibitor gp91ds-tat peptide (91ds-tat) but not scrambled control peptide ( $\mathrm{Scr}$ ) at $3 \mathrm{~h}$ reperfusion $(\boldsymbol{a})$. Samples at $3 \mathrm{~h}$ of reperfusion were also immunoprecipitated with anti-NOX2 antibody and then blotted with anti-p47phox antibody or reprobed with anti-N0X2 antibody to examine the efficiency and protein expression ( $\boldsymbol{b}$ ). Data are expressed as fold versus sham from four or five rats per group. ${ }^{\dagger} p<0.05$ versus Pla or Scr control. C, Effect of gp91ds-tat peptide on NADPH oxidase activity and superoxide production from hippocampal CA1 samples $3 \mathrm{~h}$ after ischemia, indicating that NOX2-containing NADPH oxidase is the major source of superoxide anions produced in the CA1 after ischemic reperfusion. $\boldsymbol{D}$, Representative photographs of double staining with NeuN (red) and Fluoro-Jade B (green) show that administration of gp91ds-tat peptide exerts profound neuroprotection in CA1 as determined at $7 \mathrm{~d}$ after reperfusion. CA1 cells positively stained with NeuN but not Fluoro-Jade B were identified as surviving neurons and counted per $250 \mu \mathrm{m}$ length of medial CA1 from five or six rats in each group. ${ }^{\dagger} p<0.05$ versus Pla and Scr treatment groups. Scr, gp91- scrambled tat.

Membrane NADPH oxidase "complex formation" increases in hippocampal CA1 region after GCI and is attenuated by $\mathrm{E}_{2}$ treatment

Additional studies further demonstrated that membrane levels of the NOX2 activation factors p47phox, p67phox, and Rac1 show a stepwise increase after reperfusion with peak levels observed at $3 \mathrm{~h}$ after reperfusion with levels decreasing at $6 \mathrm{~h}$ and returning to close to sham levels by $24 \mathrm{~h}$ after reperfusion (supplemental Fig. 3 , available at www.jneurosci.org as supplemental material). Total p47phox, p67phox, and Rac1 levels were not significantly changed at any time point after GCI reperfusion, suggesting that expression of the factors did not change after ischemia. As shown in Figure $4 A-C$, co-IP studies showed that complex formation of p47phox and p67phox with NOX2 is markedly increased in Pla animals compared with sham controls and that $\mathrm{E}_{2}$ significantly attenuates NOX2 complex formation with p47phox and p67phox. In agreement with these results, Western blot analysis of membrane fractions demonstrated that $\mathrm{E}_{2}$ significantly attenuated membrane translocation of p47phox and p67phox at $3 \mathrm{~h}$ after reperfusion but had no significant effect on total $\mathrm{p} 47$ phox and p67phox levels (Fig. 4D,E).

Rac1 activation is critical for NADPH oxidase activation after GCI and is significantly attenuated by $\mathrm{E}_{2}$

We next examined the activation and role of Racl in NADPH oxidase activation, $\mathrm{O}_{2}^{-}$production, and ischemic neuronal death in the CA1 region after GCI. $\mathrm{E}_{2}$ regulation of Racl activation and complex formation with NOX2 was also examined. Administration of the Racl inhibitor NSC23766 (Racl-I) intracerebroven- tricularly 30 min before GCI markedly attenuated NADPH oxidase activation and $\mathrm{O}_{2}^{-}$production in the CA1 region at $3 \mathrm{~h}$ after reperfusion (NADPH oxidase activity: vehicle, $7.70 \pm 1.32$ fold vs NSC23766, $3.32 \pm 1.25$-fold increase vs sham, $p<0.05$; superoxide levels: vehicle, $6.21 \pm 0.88$-fold vs NSC23766, $2.14 \pm$ 0.50 fold increase vs sham, $p<0.05$ ). Furthermore, as shown in Figure $5 A$, the Racl inhibitor was neuroprotective as demonstrated by an increased number of surviving neurons in the CA1 compared with a vehicle control (vehicle, $7.60 \pm 1.50$ vs NSC23766, $38.20 \pm 8.27$ surviving neurons, $p<0.05)$. Rac1GTP binding, which is critical for Racl activation, was also shown to be significantly elevated in Pla animals at $3 \mathrm{~h}$ after reperfusion compared with sham controls, and $\mathrm{E}_{2}$ attenuated this effect, suggesting that Racl activation is increased after GCI and that $\mathrm{E}_{2}$ attenuates the activation (Fig. $5 B$ ). In contrast, total Racl protein levels did not change significantly in any group. However, membrane levels of Rac1 and NOX2-Rac1 complex formation in the hippocampus CA1 were increased in the Pla group animals at $3 \mathrm{~h}$ after reperfusion compared with sham controls, and $\mathrm{E}_{2}$ treatment prevented this effect (Fig. 5C,D).

Extranuclear estrogen receptor-induced Akt signaling mediates $E_{2}$ attenuation of NADPH oxidase activation, $\mathrm{O}_{2}^{-}$production, and $\mathrm{E}_{2}$ neuroprotection after $\mathrm{GCI}$

To determine the potential role of extranuclear estrogen receptors and nongenomic signaling in $\mathrm{E}_{2}$ antioxidant and neuroprotective actions, we used EDC, an $\mathrm{E}_{2}$ conjugate that cannot enter the nuclei of cells and thus is capable of exerting nongenomic but not genomic signaling (Harrington et al., 2006). We first intracere- 

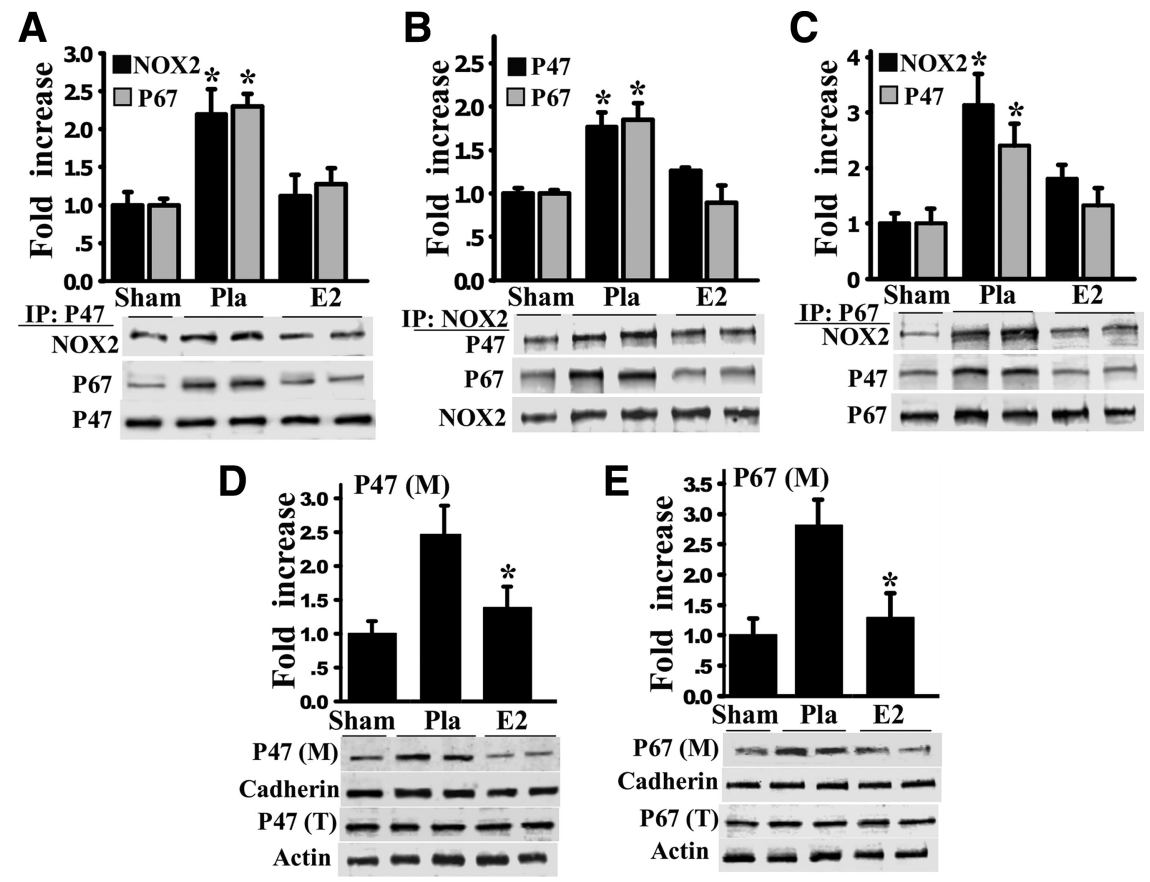

Figure 4. E2 reduces NOX2-containing NADPH oxidase complex formation in hippocampal CA1 after cerebral ischemia. $A-C$, Protein samples from the CA1 region at $3 \mathrm{~h}$ reperfusion were immunoprecipitated with anti-p47phox (P47) antibody and then separately Western blotted (WB) with anti-N0X2, p67phox (P67), or P47 antibody (A). In reciprocal Co-IP experiments, samples were subjected to IP with anti-NOX2, p67, or nonspecific lgG (control; data not shown), and the immunocomplexes were probed for the presence of $\mathrm{p} 47, \mathrm{p} 67$, and N0X2 as indicated. Data were shown as means \pm SE from independent animals $(n=$ $4-5$ ) and expressed as fold versus sham. ${ }^{\dagger} p<0.05$ versus sham and $E_{2}$ groups. $\boldsymbol{D}, \boldsymbol{E}$, Western blot analysis using membrane (M) and total (T) protein samples from $3 \mathrm{~h}$ reperfusion CA1 regions with anti-p47phox or anti-p67phox antibody. Blots were then stripped and reprobed with anti-cadherin or anti-actin antibody to show loading control. Data were expressed as fold versus sham from four or five rats. ${ }^{*} p<0.05$ versus Pla group.

broventricularly injected FITC-tagged EDC (FITC-EDC) (10 $\mu \mathrm{M}$ ) to determine its uptake in the hippocampal CA1 region and its subcellular distribution at $3 \mathrm{~h}$ after reperfusion. As shown in supplemental Figure 4 (available at www.jneurosci.org as supplemental material), FITC-EDC signal was strongly localized in the CA1 region and less so in CA3 and DG regions. Additionally, FITC-EDC signal was extranuclear, localized in the membrane and cytoplasm of cells, confirming previous reports (Harrington et al., 2006). As shown in Figure 6A, EDC administration significantly enhanced p-Akt levels in the CA1 region at $3 \mathrm{~h}$ after reperfusion, and the effect appeared to involve ER mediation because it was blocked by ICI182,780. In other studies by our group, the enhanced activation of Akt by EDC was observed as early as 10 min after GCI, and peak levels were maintained out to $3 \mathrm{~h}$ (data not shown). $E_{2}$ also enhanced p-Akt levels, and this effect was blocked by the Akt inhibitor SH-5 (Akt-I, intracerebroventricularly) (Fig. 6A). Confocal analysis of NeuN, p-Akt, and oxidized HEt staining of hippocampal sections confirmed EDC and $\mathrm{E}_{2}$ effect on enhancing p-Akt and extended the findings by demonstrating that the effect occurred in neurons (colocalized with $\mathrm{NeuN}$ ) and that cells that had enhanced p-Akt levels had correspondingly low $\mathrm{O}_{2}^{-}$production, as evidenced by low oxidized HEt staining and vice versa (Fig. $6 \mathrm{~B}$ ). Furthermore, the Akt inhibitor SH-5 reversed $\mathrm{E}_{2}$ attenuation of $\mathrm{O}_{2}^{-}$levels, confirming that Akt signaling is critical for $\mathrm{E}_{2}$ suppression of $\mathrm{O}_{2}^{-}$production. EDC also significantly attenuated the elevation of NADPH oxidase activity and $\mathrm{O}_{2}^{-}$levels in the $\mathrm{CA} 1$ region after reperfusion, an effect blocked by ICI182,780 (Fig. 6C). Intriguingly, pretreatment with the Akt inhibitor SH-5 blocked the $\mathrm{E}_{2}$ suppressive effects on NADPH oxidase activation and $\mathrm{O}_{2}^{-}$production in the
CA1 region, demonstrating a critical role for Akt in mediating $\mathrm{E}_{2}$ antioxidant effects (Fig. 6C). EDC neuroprotection was also shown to involve Akt signaling because pretreatment with $\mathrm{SH}-5$ significantly attenuated its neuroprotective effects in the CA1 region, as determined by NeuN and Fluoro-Jade B staining results (Fig. 6D). Finally, previous work by our group and others provided evidence that Akt can phosphorylate Racl at $\mathrm{Ser}^{71}$ and that this effect is correlated with reduced Racl activation (Kwon et al., 2000; Zhang et al., 2006b). We thus examined the effect of EDC and $\mathrm{E}_{2}$ on Racl phosphorylation and Rac1-GTP binding after GCI and determined the potential mediatory role of Akt. As shown in Figure $6 E$, both EDC and $\mathrm{E}_{2}$ enhanced phosphorylation of Racl at $\mathrm{Ser}^{71}$ in the CA1 region at $3 \mathrm{~h}$ after reperfusion, and their effect was correlated with a significant reduction in Racl activation. Furthermore, administration of the Akt inhibitor SH-5 markedly attenuated the ability of $\mathrm{E}_{2}$ to enhance phosphorylation of Racl and reduce Racl activation after GCI.

\section{Evidence that $\mathrm{ER} \boldsymbol{\alpha}$ mediates $\mathrm{E}_{2}$ effects to attenuate NADPH oxidase} activation, $\mathrm{O}_{2}^{-}$production, and exert neuroprotection in the hippocampus CA1 after GCI

We next sought to determine whether the antioxidant and neuroprotective effects of $E_{2}$ against cerebral ischemia were mediated by ER $\alpha$ or ER $\beta$. To determine the specific role of ER $\alpha$ and/or ER $\beta$, we used AS-ODNs to ER $\alpha$ and ER $\beta$ for knockdown of each receptor in the hippocampus. To determine that the ODNs reach the hippocampus after intracerebroventricular injection, we used Alexa488-labeled MS-ODNs (Alexa488N-MS). As shown in Figure 7A, $3 \mathrm{~h}$ after intracerebroventricular injection of Alexa488N-MS, the fluorescent Alexa488N-MS signal was predominantly localized in the hippocampal CA1 region. Additionally, double staining for NeuN revealed that the fluorescent Alexa488N-MS signal was located predominantly in the cytoplasm of neurons in the CA1 region. We next confirmed the efficacy of the ER $\alpha$ and $\mathrm{ER} \beta$ AS-ODNs in knocking down $\mathrm{ER} \alpha$ and $\mathrm{ER} \beta$ in the hippocampal CA1 region after GCI reperfusion. As shown in Figure $7 B$, the ER $\alpha$-AS-ODNs and ER $\beta$-AS-ODNs induced a marked decrease in $\operatorname{ER} \alpha$ and $\operatorname{ER} \beta$ protein levels, respectively. MS-ODNs had no effect on ER $\alpha$ or ER $\beta$ protein levels, indicating that AS-ODNs effects were specific. As shown in Figure $7 C$, ER $\alpha$-AS-ODNs but not ER $\beta$-AS-ODNs significantly reversed the suppressive effect of $\mathrm{E}_{2}$ on NADPH oxidase activation and $\mathrm{O}_{2}^{-}$production in the hippocampal CA1 region at $3 \mathrm{~h}$ after reperfusion, whereas MS-ODNs were without effect. Finally, Figure 7D shows that that ER $\alpha$-AS-ODNs, but not ER $\beta$ AS-ODNs, significantly attenuated the neuroprotective effect of $\mathrm{E}_{2}$ against GCI, suggesting that $\mathrm{ER} \alpha$ mediates the neuroprotective actions of $E_{2}$ in the hippocampus CA1. MS control oligos had no significant effect, indicating the specificity of the ER $\alpha$-AS effect. 
Long-term $\mathrm{E}_{2}$ deprivation leads to loss

of $E_{2}$ nongenomic signaling,

antioxidant, and neuroprotective

effects in the hippocampus CA1 after

GCI, whereas $\mathrm{E}_{2}$ uterotropic effects are preserved

It has been proposed that the lack of beneficial cardiovascular and cognitive effect of $\mathrm{E}_{2}$ in the WHI studies could be attributable to estrogen replacement therapy being initiated in subjects too far past menopause, e.g., after too long a period of $\mathrm{E}_{2}$ deprivation. We thus examined whether a period of long-term $\mathrm{E}_{2}$ deprivation (10 weeks) would lead to diminishment of $\mathrm{E}_{2}$ signaling and actions in the hippocampal CA1 region after GCI. Additionally, the tropic effect of $E_{2}$ on the uterus was examined to determine whether changes in $\mathrm{E}_{2}$ sensitivity after long-term $\mathrm{E}_{2}$ deprivation were brain specific. As shown in Figure $8 A$, the ability of $E_{2}$ to exert neuroprotection in the hippocampal CA1 region is lost in longterm $\mathrm{E}_{2}$-deprived animals, as determined by NeuN and Fluoro-Jade B staining and counting of number of surviving neurons. Additionally, the ability of $\mathrm{E}_{2}$ to suppress $\mathrm{NADPH}$ oxidase activation and $\mathrm{O}_{2}^{-}$production in the CA1 region at $3 \mathrm{~h}$ after reperfusion was lost in long-term $\mathrm{E}_{2}$-deprived animals (NADPH oxidase activity: Pla, $7.20 \pm 0.65$-fold vs $\mathrm{E}_{2}, 6.83 \pm 0.88$-fold increase vs sham, no significant difference; superoxide levels: Pla, $5.81 \pm 0.56$-fold vs $\mathrm{E}_{2}$, $5.28 \pm 0.96$-fold increase vs sham, no significant difference). The ability of $\mathrm{E}_{2}$ to enhance Akt phosphorylation in the CA1 region at $3 \mathrm{~h}$ after reperfusion was also lost in long-term $\mathrm{E}_{2}$-deprived animals (Fig. $8 \mathrm{~B}$ ). Previous work has shown that $\mathrm{ER} \alpha$ can interact with the $\mathrm{p} 85$ regulator subunit of $\mathrm{PI} 3 \mathrm{~K}$, an effect enhanced by $\mathrm{E}_{2}$ treatment and critical for its ability to enhance phosphorylation of Akt (Simoncini et al., 2000). We thus performed co-IP studies for ER $\alpha$ and $\mathrm{p} 85$ from hippocampal CA1 samples at $3 \mathrm{~h}$ after GCI in immediate $\mathrm{E}_{2}$-treated (Imm) ovariectomized animals and in long-term $\mathrm{E}_{2}$-deprived animals $(10 \mathrm{~W})$. As shown in Figure $8 B, \mathrm{E}_{2}$ enhanced $\mathrm{ER} \alpha$ and p 85 subunit interaction in the hippocampus CA1 in Imm animals, but this ability was lost in long-term $\mathrm{E}_{2}$-deprived animals $(10 \mathrm{~W})$. Additionally, examination of NeuN and Fluoro-Jade B staining and counting of the number of surviving neurons in the CA1 revealed that the neuroprotective effect of EDC is lost in 10W animals (Fig. 8C) (vehicle, 8.25 4.10 vs EDC, $12.26 \pm 6.12$ surviving neurons, no significant difference), as was its ability to enhance Akt phosphorylation (Fig. $8 D$ ) However, in contrast to the loss of $\mathrm{E}_{2}$ sensitivity observed in the hippocampus CA1 of 10W animals, the well known uterotrophic effect of $\mathrm{E}_{2}$ on the uterus was not lost in $10 \mathrm{~W}$ animals, indicating that loss of $\mathrm{E}_{2}$ sensitivity after long-term $\mathrm{E}_{2}$ deprivation is tissue-specific (Fig. $8 E$ ).

$\mathrm{ER} \boldsymbol{\alpha}$, but not $\mathrm{ER} \boldsymbol{\beta}$, protein levels are significantly reduced in the hippocampal CA1 region after long-term $\mathrm{E}_{2}$ deprivation Because $\mathrm{E}_{2}$ signaling and actions in the hippocampus were attenuated in long-term $\mathrm{E}_{2}$-deprived animals but its uterotrophic ac- tion in the uterus was preserved, we examined the hippocampal $\mathrm{CA} 1$ region and uterus for alterations in $\mathrm{ER} \alpha$ and $\mathrm{ER} \beta$ after longterm $\mathrm{E}_{2}$ deprivation. As shown in Figure 9A, Western blot analysis revealed a dramatic attenuation of $\mathrm{ER} \alpha$, but not $\mathrm{ER} \beta$, protein levels in the hippocampal CA1 region of 10W animals compared with Imm animals. Note that the reduction in $\mathrm{ER} \alpha$ protein levels occurred in all groups, including sham controls, suggesting that long-term $\mathrm{E}_{2}$ deprivation leads to lower $\mathrm{ER} \alpha$ levels regardless of treatment and that $\mathrm{E}_{2}$ and ischemia cannot reverse the suppression of $\mathrm{ER} \alpha$ protein levels. Figure $9 B$ shows double immunohistochemistry for NeuN and $\mathrm{ER} \alpha$ in the CA1 region in Imm and $10 \mathrm{~W}$ animals, which further confirms that $\mathrm{ER} \alpha$ expression in hippocampal CA1 neurons is strongly attenuated in 10W animals compared with Imm animals; note the marked attenuation of "green" ER $\alpha$ signal and "yellow" ER $\alpha-\mathrm{NeuN}$ merged signal in $10 \mathrm{~W}$ animals. In contrast, examination of the uterus revealed no significant change of $\mathrm{ER} \alpha$ or $\mathrm{ER} \beta$ protein levels in 10W animals compared with Imm animals (Fig. 9C). Furthermore, $\mathrm{E}_{2}$ exerted a well characterized rapid downregulation of $\operatorname{ER} \alpha$ and $\operatorname{ER} \beta$ in the uterus of Imm animals consistent with other reports in the literature (Medlock et al., 1991; Nephew et al., 2000; Pillai et al., 2002; Kang et al., 2003), and this effect was preserved in 10W animals. This finding further confirms that $\mathrm{E}_{2}$ sensitivity and $\mathrm{ER} \alpha / \beta$ protein levels are not attenuated in the uterus after a long-term period of $\mathrm{E}_{2}$ deprivation. 

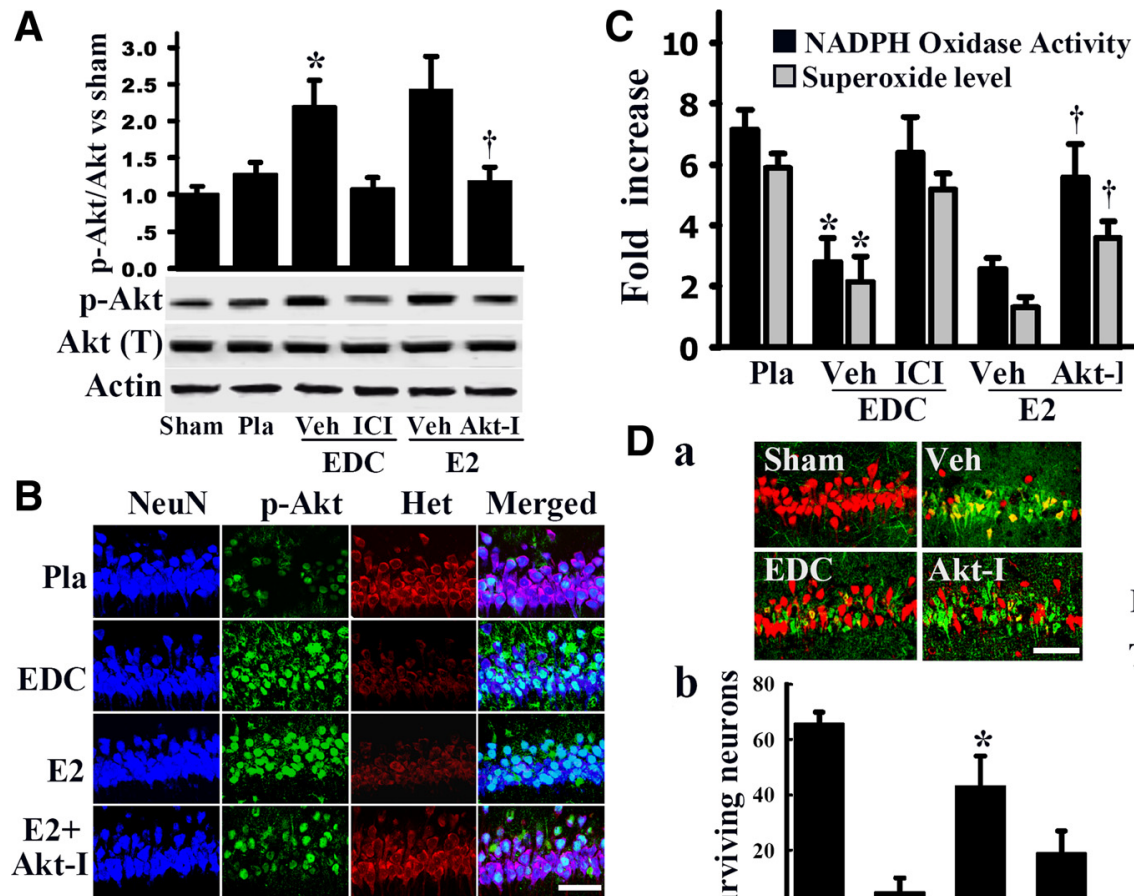

\section{E}
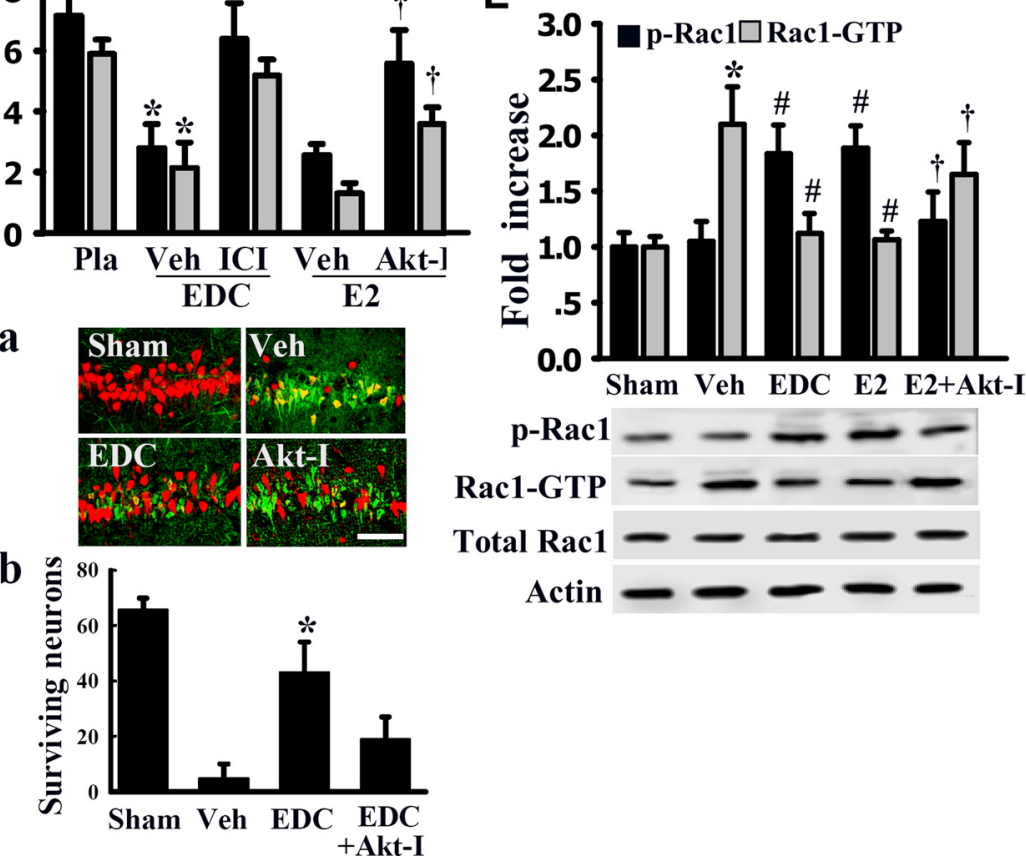

Figure 6. Evidence that an extranuclear estrogen receptor mediates $\mathrm{E}_{2}$ attenuation of NADPH oxidase activity, superoxide levels, and the neuroprotection-associated activation of Akt signaling. $\boldsymbol{A}$, Western blot analyses of extranuclear estrogen receptor-mediated Akt activation by $\mathrm{E}_{2}$ and the effect of an Akt inhibitor (Akt-I, SH-5' $50 \mu \mathrm{g} / \mathrm{rat}$ ) and the ER antagonist $\mathrm{ICl} 182,780$ (ICI) on Akt activation induced by $\mathrm{E}_{2}$ from CA1 samples at $3 \mathrm{~h}$ reperfusion. ${ }^{*} p<0.05$ versus Pla or ICI $+\mathrm{EDC}$ group; ${ }^{\dagger} p<0.05$ versus $\mathrm{E}_{2}+$ vehicle $($ Veh) treatment group. $\boldsymbol{B}$, Typical examples of triple-labeling immunofluorescence using oxidized HEt (red) and antibodies to NeuN (blue) and phospho-Akt (green) on medial CA1 sections $3 \mathrm{~h}$ after reperfusion. Note that Akt was markedly activated either by EDC or $\mathrm{E}_{2}$ treatment in neuronal cells, an effect that correlated with lower superoxide levels compared with Pla control. The effects were reversed when Akt activation was inhibited by Akt-I. C, Assay of NADPH oxidase activity and superoxide levels from CA1 samples $3 \mathrm{~h}$ after ischemia, demonstrating ER dependency of EDC effects and the role of Akt activation in $\mathrm{E}_{2}$ actions. ${ }^{*} p<0.05$ versus Pla or $\mathrm{ICI}+\mathrm{EDC}$ group; ${ }^{\dagger} p<0.05$ versus $\mathrm{E}_{2}+$ vehicle group. $\boldsymbol{D}$, Representative double staining with NeuN (red) and Fluoro-Jade B (green) of medial CA1 subregions provides evidence that EDC activation of Akt has an important role in EDC-induced neuroprotection because Akt-I markedly attenuates $E D C$ neuroprotection. ${ }^{*} p<0.05$ versus vehicle or EDC + Akt-I group. Scale bar, $50 \mu \mathrm{m}$. Magnification, $40 \times$. $\boldsymbol{E}$, Western blot analyses on the indicated CA1 samples at $3 \mathrm{~h}$ reperfusion showing EDC- or $E_{2}$-mediated increase of Rac1 phosphorylation on $\mathrm{Ser}^{71}$ residue and the attenuation of Rac1-GTP binding compared with vehicle control and the effects of an Akt inhibitor (Akt-I) on Rac1 phosphorylation and activation. Total Rac1 was not changed in all the groups. Data are means \pm SE from four or five rats in each group, and values are expressed as fold versus sham. ${ }^{*} p<0.05$ versus sham; ${ }^{\#} p<0.05$ versus vehicle group; ${ }^{\dagger} p<0.05$ versus $\mathrm{E}_{2}$ or $\mathrm{EDC}$ group.

Long-term $\mathrm{E}_{2}$ deprivation leads to hypersensitivity of the hippocampal CA3/CA4 region to ischemic neuronal cell death Additional examination of long-term $\mathrm{E}_{2}$-deprived animals revealed that prolonged $\mathrm{E}_{2}$ deprivation leads to hypersensitivity of hippocampal CA3/CA4 neurons to ischemic cell death after GCI. As shown in Figure $10 \mathrm{~A}$, sham animals from Imm or 10W groups show no damage or cell loss in any hippocampal region, as assessed by NeuN staining. In contrast, the Imm placebo-treated (Pla) group displayed a dramatic loss of neurons in the CA1 region but not CA3/CA4 or DG region of the hippocampus at $7 \mathrm{~d}$ after $10 \mathrm{~min}$ GCI. Of significant interest, 10W Pla animals displayed a dramatic loss of cells not only in the CA1 region but also in the CA3/CA4 region after 10 min GCI, suggesting an enhanced sensitivity of the CA3/CA4 to ischemic damage after long-term $\mathrm{E}_{2}$ deprivation (Fig. $10 \mathrm{~A}$ ). Figure $10 \mathrm{~B}$ shows that $\mathrm{E}_{2}$ treatment of Imm animals profoundly protects the CA1 region from ischemic damage as expected. It also shows that $\mathrm{ER} \alpha$ is highly expressed in the surviving cells in the CA1 region and also CA3 region. In contrast, Figure $10 \mathrm{Bb}$ reveals that $\mathrm{E}_{2}$ treatment initiated 10 weeks after ovariectomy does not protect the CA1 region and is unable to protect the CA3/CA4 region from ischemic damage. However, it is noteworthy that the few surviving cells in the CA1 and CA3 region at $7 \mathrm{~d}$ after reperfusion strongly express $\mathrm{ER} \alpha$ (Fig. $10 \mathrm{~B}$, yellow merged cells).

\section{Discussion}

It is well known that ischemic reperfusion can induce significant damage to the brain attributable to the enhanced generation of ROS, such as the highly reactive $\mathrm{O}_{2}^{-}$ion (Chan, 1996; Peters et al., 1998; Sugawara et al., 2005; Muranyi and Li, 2006; Brann et al., 2007), which can give rise to other damaging ROS such as hydroxyl ion and peroxynitrite (Mattson et al., 2000). The current study provides evidence that the membrane enzyme NADPH oxidase plays a major role in the generation of $\mathrm{O}_{2}^{-}$in the hippocampal CA1 region after ischemic reperfusion and that inhibition of NADPH oxidase activation by either a competitive NADPH oxidase inhibitor (gp91ds-tat) or $\mathrm{E}_{2}$ treatment profoundly protects the hippocampal CA1 region from oxidative damage and neuronal cell death. The source of NADPH oxidase activity and $\mathrm{O}_{2}^{-}$generation after ischemic reperfusion appears to be primarily neuronal, because enhancement of oxidized HEt, an in situ marker of $\mathrm{O}_{2}^{-}$production, occurred predominantly in neurons. Furthermore, both NOX2 and p47phox were highly colocalized in neurons but not in glia after GCI.

Our study suggests that the NOX2 isoform of NADPH oxidase has a critical role in the enhanced NADPH oxidase activation and $\mathrm{O}_{2}^{-}$production after GCI, because NOX2 and p47phox were highly colocalized in CA1 neurons, and NOX2-phox complex 
formation increased significantly at $3 \mathrm{~h}$ after GCI reperfusion, the time of peak NADPH oxidase activity and $\mathrm{O}_{2}^{-}$production. Furthermore, administration of the competitive NOX2 NADPH oxidase inhibitor gp9lds-tat dramatically attenuated NADPH oxidase activation and $\mathrm{O}_{2}^{-}$production after reperfusion and strongly attenuated neuronal cell death. NOX2 activation is also known to require activated Racl (Bedard and Krause, 2007), and our study showed that a Rac1 inhibitor strongly reduced NADPH oxidase activation and $\mathrm{O}_{2}^{-}$production after GCI, further implicating NOX2. Additional work by others suggests that NOX2 also has a role in oxidative damage in the cerebral cortex, because cortical infarct damage was reduced after MCAO in NOX2 knock-out mice or after administration of the NADPH oxidase inhibitor apocynin (Kahles et al., 2007; Tang et al., 2008; Chen et al., 2009). Thus, NOX2 NADPH oxidase appears to play a major role in ischemic ROS generation and oxidative damage in the brain. It is important to note that, in our study, the hippocampal CA3/DG region, in contrast to the CA1 region, showed very low expression of NOX2 and phox subunits and did not exhibit a significant elevation of $\mathrm{NADPH}$ oxidase activity or $\mathrm{O}_{2}^{-}$production after GCI reperfusion. It is thus tempting to speculate that the low expression and activation of NADPH oxidase in the hippocampal CA3/DG region after GCI reperfusion may contribute to its well known resistance to ischemic damage.

Our study also showed that $\mathrm{E}_{2}$ profoundly attenuates neuronal NADPH oxidase activation and $\mathrm{O}_{2}^{-}$production in the CA1 region after GCI reperfusion. This effect appeared specific for the ischemic situation, because $\mathrm{E}_{2}$-treated sham animals did not show reduced NADPH oxidase activity or $\mathrm{O}_{2}^{-}$levels compared with vehicle-treated sham controls. Additionally, the mechanism of action of $\mathrm{E}_{2}$ suppression of NADPH oxidase activation and $\mathrm{O}_{2}^{-}$ generation was shown to involve attenuation of Racl activation, which is known to be critical for NOX2 complex formation and activation. $\mathrm{E}_{2}$ did not significantly affect protein expression levels of NOX2, p47phox, p67phox, or Rac1 in the hippocampal CA1 region. Rather, $\mathrm{E}_{2}$ enhanced phosphorylation of Rac1 at $\mathrm{Ser}^{71}$, an effect that involved Akt mediation. Previous work has shown that phosphorylation of Racl at Ser ${ }^{71}$ leads to inhibition of Rac1-GTP binding, which is critical for Racl activation (Zhang et al., $2006 \mathrm{~b})$. In agreement with this, our study showed that $E_{2}$ and EDC enhancement of $\mathrm{p}$-Racl levels was correlated with reduced Rac1-GTP binding. NOX2 NADPH oxidase has also been demonstrated recently to have a significant role in Alzheimer's disease pathology (Block, 2008; Park et al., 2008), and thus our observed $\mathrm{E}_{2}$ mechanism of strongly inhibiting NADPH oxidase activation and ROS generation could also have relevance to $\mathrm{E}_{2}$ beneficial effects in Alzheimer's disease. This possibility awaits additional study. We should add that the effects of $\mathrm{E}_{2}$ on NADPH oxidase, Rac1, and Akt were shown to be ER mediated because they were

\section{$C_{\text {a }}$}

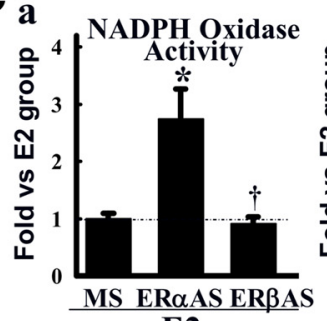

E2
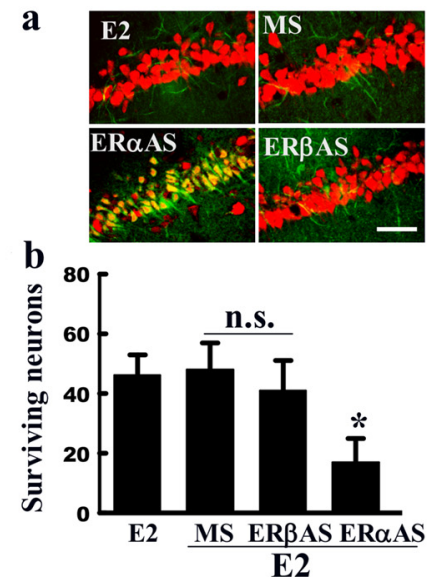

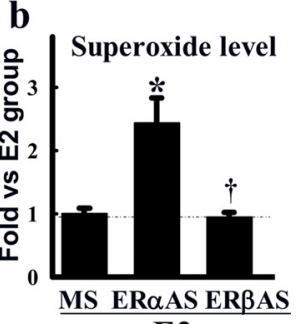

E2

Figure 7. Evidence that $\mathrm{ER} \alpha$ mediates $\mathrm{E}_{2}$-induced attenuation of $\mathrm{NADPH}$ activity and superoxide production as well as $\mathrm{E}_{2}$ -

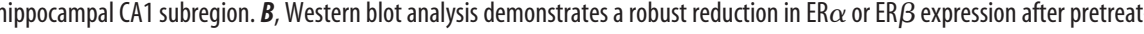
hippocampus $(\boldsymbol{a})$. Values are means $\pm \mathrm{SE}$ from six to seven animals $(\boldsymbol{b}) .{ }^{*} p<0.05$ versus $\mathrm{E}_{2}+\mathrm{MS}$ group. Scale bars, $50 \mu \mathrm{m}$. Magnification, $40 \times$. n.S., No significant difference.

blocked by acute treatment with the ER antagonist ICI182,780. The ability of acute ICI182,780 treatment to block $\mathrm{E}_{2}$ neuroprotection, in which $\mathrm{E}_{2}$ was administered for 1 week before GCI, suggests that $\mathrm{E}_{2}$ actions immediately after ischemia are critically important for the neuroprotective effect of $E_{2}$. In particular, based on the results of our study, $\mathrm{E}_{2}$ action to modulate activation of prosurvival factors (e.g., Akt) and oxidative prodeath pathways (e.g., Rac1 and NADPH oxidase/ROS) early after cerebral ischemia appear key to the ability of $\mathrm{E}_{2}$ to exert neuroprotection in the hippocampal CA1 region, and ICI182,780 blocked these key $\mathrm{E}_{2}$ actions.

It should be noted that, although the CA3/DG region had high $\mathrm{ER} \alpha$ levels, $\mathrm{E}_{2}$ had no significant effect on NADPH oxidase activation or $\mathrm{O}_{2}^{-}$levels in this hippocampal region. However, the CA3/DG region did not display a significant reperfusion-induced increase in NADPH oxidase activation or $\mathrm{O}_{2}^{-}$levels after stroke, which may explain the lack of significant $\mathrm{E}_{2}$ effect (e.g., there was no significant elevation for $\mathrm{E}_{2}$ to inhibit). Our study also provided evidence that extranuclear ER $\alpha$-mediated signaling contributes significantly to $E_{2}$ neuroprotective effects in the CA1 region after GCI. Use of EDC, a cell-impermeable $\mathrm{E}_{2}$ conjugate that interacts with extranuclear ER but not nuclear ER (Harrington et al., 2006), suppressed NADPH oxidase activation and $\mathrm{O}_{2}^{-}$production but rapidly stimulated Akt activation and neuroprotection. EDC neuroprotection was blocked by the ER antagonist ICI182,780 and 
A

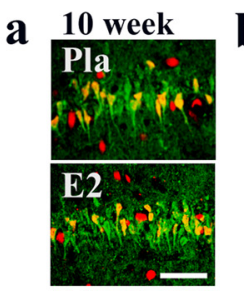

B

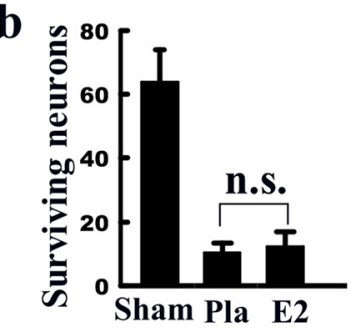

a

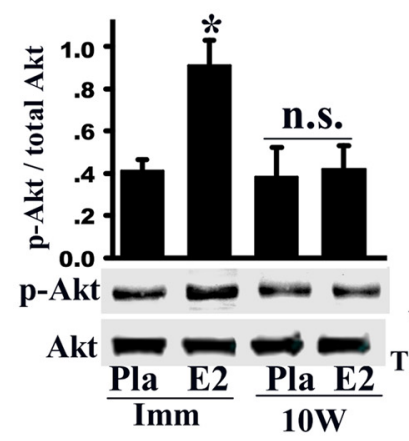

b

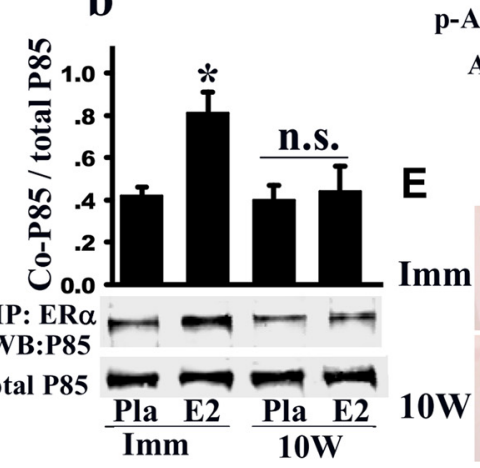

C

D
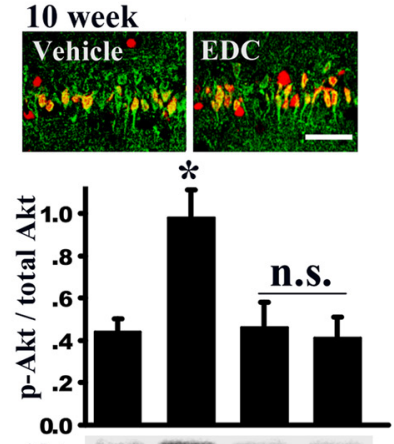

-Akt

Akt

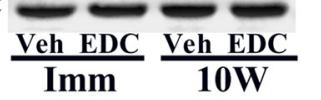

Figure 8. Loss of nongenomic signaling and neuroprotective actions of $E_{2}$ in the hippocampus after long-term $E_{2}$ deprivation. $A$, NeuN (red) and Fluoro-Jade $B$ (green) staining results in hippocampal $C A 1$ of long-term $E_{2}$-deprived animals treated with $E_{2}$ or Pla. Note that $E_{2}$ loses its ability to protect $C A 1$ neurons against ischemic damage after long-term $E_{2}$ deprivation. $B$, Effect of long-term $E_{2}$ deprivation on nongenomic signaling by $E_{2}$. Hippocampal $C A 1$ protein lysate samples at $3 \mathrm{~h}$ reperfusion from Imm and $10 \mathrm{~W} \mathrm{E}_{2}$-replaced rats were analyzed by Western blot for $\mathrm{p}$-Akt and Akt levels $(\boldsymbol{a}) \cdot \boldsymbol{b}$, Samples were immunoprecipitated with anti-ER $\alpha$ antibody and blotted with anti-p85 subunit of PI3K. Equal amount of protein was also Western blotted with anti-p85 to examine the total protein expression. ${ }^{*} p<0.05$ versus Pla and $10 \mathrm{~W} \mathrm{E}_{2}$ groups. $C$, NeuN (red) and Fluoro-Jade B (green) staining reveals that EDC neuroprotection is lost in $10 \mathrm{~W}$ animals. $\boldsymbol{D}$, EDC loses the ability to activate Akt after 10 weeks of $E_{2}$ deprivation. ${ }^{*} p<0.05$ versus vehicle and 10 week $E D C$ groups. n.s., No significant difference. $E$, In contrast to loss of $E_{2}$ neural actions after long-term $E_{2}$ deprivation, the trophic effect of $E_{2}$ on the uterus is not lost after 10 weeks of $E_{2}$ deprivation. Scale bars, $1 \mathrm{~cm}$. Magnification, $1 \times$.

A

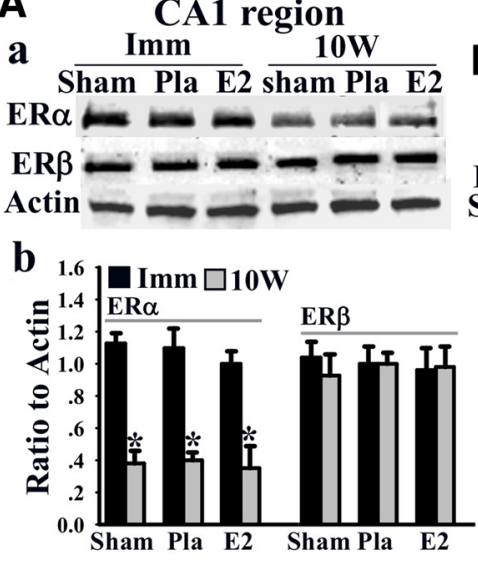

C
B

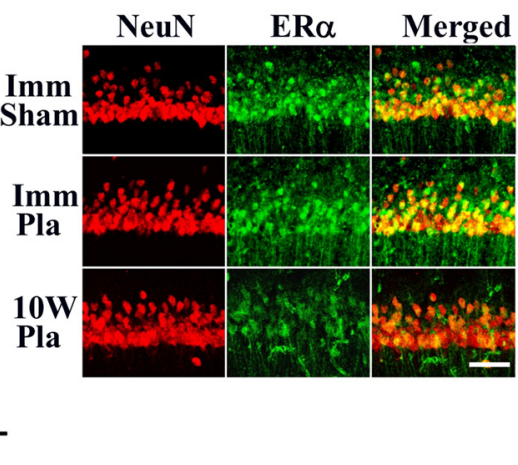

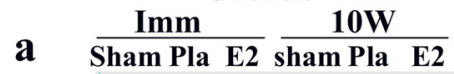

$\mathrm{ER} \alpha--$
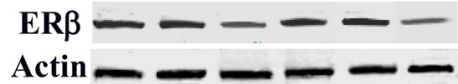

b

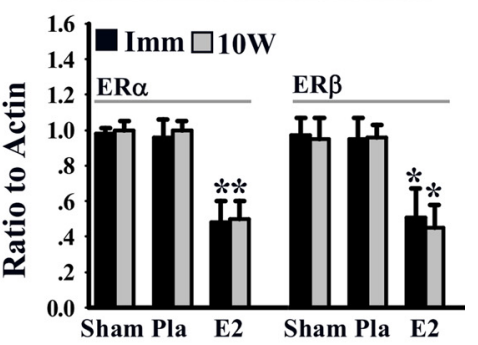

Figure 9. Long-term $E_{2}$ deprivation leads to a significant loss of $E R \alpha$, but not $E R \beta$, in the hippocampus $C A 1$ in all groups, including sham non-ischemic animals, whereas $E R \alpha$ and $E R \beta$ levels are unchanged in the uterus of 10 week $E_{2}$-deprived animals, and the $E_{2}$ regulatory effect to decrease $E R \alpha$ and $E R \beta$ in the uterus is preserved. $A$, Western blot analyses on the indicated $C A 1$ samples from sham and $3 \mathrm{~h}$ reperfusion in Imm and $10 \mathrm{~W}$ animals after global cerebral ischemia $(\boldsymbol{a})$, showing reduction of ER $\alpha$ but not ER $\beta$ expression in the $10 \mathrm{~W}$ rats in all groups compared with Imm animals. Data were shown as means \pm SE from four to six rats in each group and expressed as ratio to actin $(\boldsymbol{b}) .{ }^{*} p<0.05$ versus Imm group. $\boldsymbol{B}$, Typical confocal microscopy examples of double labeling using anti-NeuN (red) and anti-ER $\alpha$ (green) antibodies on sham and $3 \mathrm{~h}$ reperfusion sections confirming decreased ER $\alpha$ in CA1 neurons after long-term $\mathrm{E}_{2}$ deprivation. Scale bar, $50 \mu \mathrm{m}$. Magnification, $40 \times$. C, Western blots showing $E R \alpha$ and $E R \beta$ expression after immediate or 10 week $E_{2}$ deprivation in uterus total protein samples. Note that 10 weeks of $E_{2}$ deprivation failed to downregulate ER $\alpha$ protein expression in the uterus as was observed in the CA1 region. However, both $E R \alpha$ and $E R \beta$ expression in the uterus was attenuated by $E_{2}$ compared with Pla control, and this effect was maintained in 10 week $E_{2}$-deprived animals. Values were shown as means \pm SE in each group $(n=4-6)$ and expressed as ratio to actin. ${ }^{*} p<0.05$ versus Pla group.

by the AkT inhibitor SH-5, demonstrating that its effects are ER mediated and involve Akt activation.

The antioxidant and neuroprotective effect of $\mathrm{E}_{2}$ in our study appeared to be mediated primarily by $\mathrm{ER} \alpha$, because antisense oligonucleotide knockdown of $\mathrm{ER} \alpha$ but not $\mathrm{ER} \beta$ resulted in a loss of NADPH oxidase and $\mathrm{O}_{2}^{-}$regulatory effects and neuroprotection by $\mathrm{E}_{2}$. Furthermore, the antioxidant and neuroprotective effects of $E_{2}$ were lost in long-term $E_{2}$-deprived animals, which displayed a loss of $\mathrm{ER} \alpha$ but not $\mathrm{ER} \beta$ in the hippocampal CA1 region. Previous work had suggested that both ER $\alpha$ and ER $\beta$ may 
A

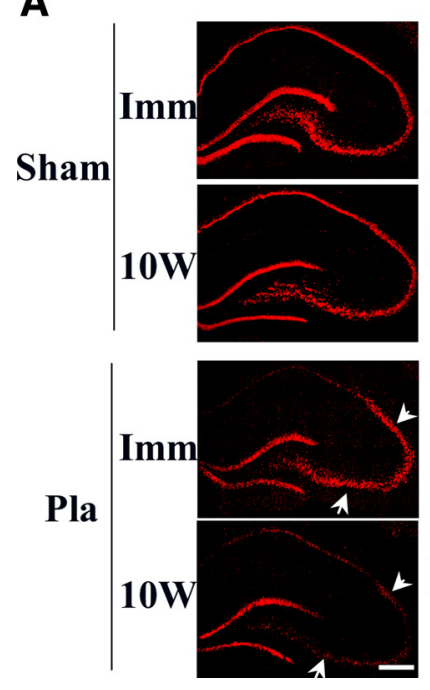

B
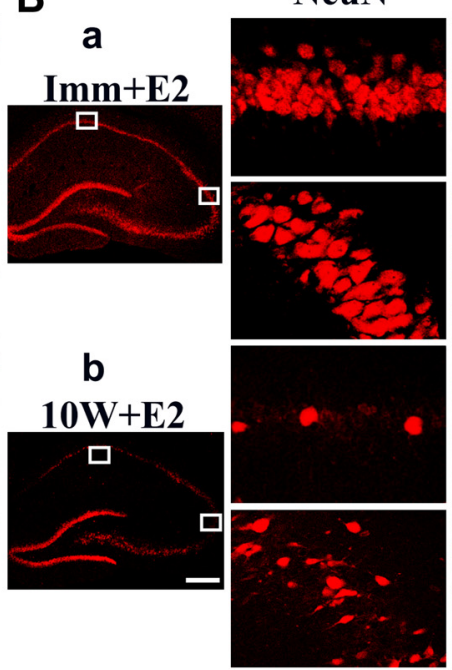

$\mathrm{ER} \alpha$
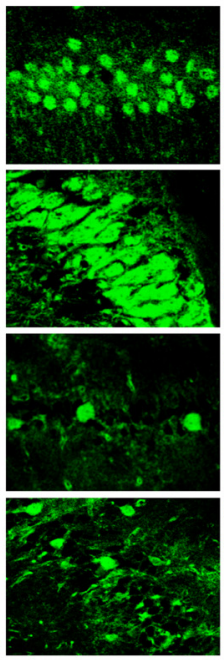

Merged

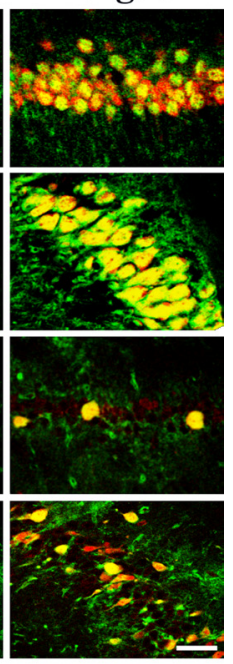

Figure 10. Long-term $E_{2}$ deprivation leads to hypersensitivity of CA3/CA4 neurons to ischemic cell death after 10 min global cerebral ischemia, and $E_{2}$ replacement is incapable of exerting neuroprotection or reversing the CA3/CA4 hypersensitivity to ischemic damage. $A$, Typical microscopy images showing NeuN staining in hippocampus from sham or Pla-treated Imm or $10 \mathrm{~W}$ ovariectomized rats. Note the increased sensitivity of the CA3/CA4 region in Pla 10W animals to neuronal cell death, as evidenced by loss of NeuN staining. $\boldsymbol{B}$, Representative photomicrographs of NeuN and $E R \alpha$ staining in CA1 and CA3 at $7 \mathrm{~d}$ after 10 min global cerebral ischemia in $E_{2}$-treated Imm or $10 \mathrm{~W}$ rats. Note that NeuN staining colocalized well with ER $\alpha$ staining in the few healthy $C A 3$ neurons in $10 \mathrm{~W}$ animals, suggesting that $\mathrm{CA} 3$ neurons that maintain $\mathrm{ER} \alpha$ may have greater protection against neuronal cell death. $\boldsymbol{A}, \boldsymbol{B} \boldsymbol{a}, \boldsymbol{B} \boldsymbol{b}$ : magnification, $5 \times$; scale bar, $200 \mu \mathrm{m}$. Right: magnification, $40 \times$; scale bar, $50 \mu \mathrm{m}$.

mediate $\mathrm{E}_{2}$ neuroprotective effects in the CA1 after GCI based on results using putative ER-selective agonists (Miller et al., 2005), but the selectivity of the agonists was not confirmed. Based on our studies using AS-ODN knockdown of each ER isoform, we conclude that $\mathrm{ER} \alpha$ is the principal mediator of $\mathrm{E}_{2}$ neuroprotective actions in the hippocampal CA1 region after GCI.

Our study also provides important support for the critical period hypothesis for $\mathrm{E}_{2}$ beneficial effect (Maki, 2006; Sherwin, 2007a; Suzuki et al., 2007; Sherwin and Henry, 2008), because we observed that long-term $\mathrm{E}_{2}$ deprivation resulted in a complete loss of $\mathrm{E}_{2}$ nongenomic signaling, antioxidant actions, and neuroprotective effects in the hippocampal CA1 region. Intriguingly, the loss of $\mathrm{E}_{2}$ sensitivity was tissue specific, because the uterotrophic effect of $\mathrm{E}_{2}$ was not lost. Paralleling, and potentially explaining, the tissue-specific loss of $\mathrm{E}_{2}$ sensitivity was our observation of a loss of $\mathrm{ER} \alpha$ (but not $\mathrm{ER} \beta$ ) in the hippocampus CA1 region but not in the uterus after long-term $\mathrm{E}_{2}$ deprivation. In previous work in the rat cerebral cortex, Suzuki et al. (2007) reported an ischemia-induced elevation of $\mathrm{ER} \alpha$ in the cerebral cortex after $\mathrm{MCAO}$, an effect that was lost in long-term $\mathrm{E}_{2}$-deprived rats. However, our results in the hippocampal CA1 region differ, because we observed a loss of ER $\alpha$ in the CA1 region in all groups (including sham controls), suggesting a loss of basal ER $\alpha$ independent of treatment or injury. A similar loss of basal ER $\alpha$ levels has been reported to occur in the aorta after prolonged $\mathrm{E}_{2}$ deprivation, suggesting that the loss of basal ER $\alpha$ occurs in both neural and vascular tissues (Pinna et al., 2008). Currently, it is unknown as to why $\mathrm{ER} \alpha$ is lost in the hippocampal CA1 region but not in the uterus after prolonged hypoestrogenicity. Additional work is needed to address the mechanism of this tissue-specific loss of $\mathrm{ER} \alpha$.

Finally, an additional novel observation derived from our studies was that we observed a dramatically enhanced hypersensitivity of the hippocampal CA3/CA4 region to ischemic injury and neuronal cell death after long-term $\mathrm{E}_{2}$ deprivation. This is intriguing because long-term ovariectomy (surgical menopause) in humans has been correlated with an increased risk of cognitive decline and dementia, although the mechanisms underlying the effects have remained unclear (Rocca et al., 2007, 2008; Shuster et al., 2008). Our study may provide a mechanistic explanation for this increased risk by demonstrating a hypersensitivity of the hippocampal CA3/CA4 to injury after prolonged hypoestrogenicity. Sham animals showed no loss of CA3/CA4 neurons after prolonged hypoestrogenicity, suggesting that the ability of the CA3/ CA4 to withstand a severe stress after prolonged hypoestrogenicity is severely compromised and that $\mathrm{E}_{2}$ deprivation itself, per se, does not cause loss of CA3/CA4 neurons. $\mathrm{E}_{2}$ treatment begun after prolonged hypoestrogenicity did not prevent the induction of the CA3/CA4 hypersensitivity, which may be attributable to a loss of $\mathrm{E}_{2}$ sensitivity of this region, as shown for the CA1 region. Additional studies are needed to determine whether $\mathrm{E}_{2}$ treatment initiated before the period of prolonged hypoestrogenicity would protect the CA3/CA4 region and prevent the induction of the ischemic hypersensitivity. One caveat of our studies is that young adult animals were used, and it is unclear whether aged animals would display a similar result. Thus, studies in aged animals are needed to further assess age-related alterations of $E_{2}$ sensitivity and neuroprotection in the hippocampus. However, it should be mentioned that surgical menopause (ovariectomy) produces hypoestrogenicity at an early age in humans, which is similar to our model. Furthermore, surgical menopause in humans is associated with increased risk of cognitive decline, dementia, and cardiovascular disease (Shuster et al., 2008).

In conclusion, the current study advances the field by elucidating a novel and potent extranuclear ER $\alpha$-mediated action of $\mathrm{E}_{2}$ in the brain to suppress NADPH oxidase activation and $\mathrm{O}_{2}^{-}$generation in hippocampal CA1 neurons after stroke. It also provides important evidence supporting a critical period for $E_{2}$ neuroprotective actions in the hippocampus and demonstrates a tissue-specific loss of $\mathrm{E}_{2}$ action and basal $\mathrm{ER} \alpha$ expression, which may explain how and why the critical period exists. Finally, it demonstrates that the often ignored CA3/CA4 becomes hypersensitive to injury after long-term $\mathrm{E}_{2}$ deprivation, which may help explain the increased risk of cognitive decline and dementia ob- 
served after prolonged hypoestrogenicity or long-term ovariectomy in women.

\section{References}

Anderson GL, Limacher M, Assaf AR, Bassford T, Beresford SA, Black H, Bonds D, Brunner R, Brzyski R, Caan B, Chlebowski R, Curb D, Gass M, Hays J, Heiss G, Hendrix S, Howard BV, Hsia J, Hubbell A, Jackson R, et al. (2004) Effects of conjugated equine estrogen in postmenopausal women with hysterectomy: the Women's Health Initiative randomized controlled trial. JAMA 291:1701-1712.

Bedard K, Krause KH (2007) The NOX family of ROS-generating NADPH oxidases: physiology and pathophysiology. Physiol Rev 87:245-313.

Bindokas VP, Jordán J, Lee CC, Miller RJ (1996) Superoxide production in rat hippocampal neurons: selective imaging with hydroethidine. J Neurosci $16: 1324-1336$

Block ML (2008) NADPH oxidase as a therapeutic target in Alzheimer's disease. BMC Neurosci 9 [Suppl 2]:S8.

Brann DW, Dhandapani K, Wakade C, Mahesh VB, Khan MM (2007) Neurotrophic and neuroprotective actions of estrogen: basic mechanisms and clinical implications. Steroids 72:381-405.

Chan PH (1996) Role of oxidants in ischemic brain damage. Stroke 27:1124-1129.

Chen H, Song YS, Chan PH (2009) Inhibition of NADPH oxidase is neuroprotective after ischemia-reperfusion. J Cereb Blood Flow Metab 29:1262-1272.

Di Carlo A, Lamassa M, Baldereschi M, Pracucci G, Basile AM, Wolfe CD, Giroud M, Rudd A, Ghetti A, Inzitari D (2003) Sex differences in the clinical presentation, resource use, and 3-month outcome of acute stroke in Europe: data from a multicenter multinational hospital-based registry. Stroke 34:1114-1119.

Edinger KL, Frye CA (2007) Androgens' effects to enhance learning may be mediated in part through actions at estrogen receptor-beta in the hippocampus. Neurobiol Learn Mem 87:78-85.

Espeland MA, Rapp SR, Shumaker SA, Brunner R, Manson JE, Sherwin BB, Hsia J, Margolis KL, Hogan PE, Wallace R, Dailey M, Freeman R, Hays J (2004) Conjugated equine estrogens and global cognitive function in postmenopausal women: Women's Health Initiative Memory Study. JAMA 291:2959-2968.

Harrington WR, Kim SH, Funk CC, Madak-Erdogan Z, Schiff R, Katzenellenbogen JA, Katzenellenbogen BS (2006) Estrogen dendrimer conjugates that preferentially activate extranuclear, nongenomic versus genomic pathways of estrogen action. Mol Endocrinol 20:491-502.

Henderson VW (2008) Cognitive changes after menopause: influence of estrogen. Clin Obstet Gynecol 51:618-626.

Kahles T, Luedike P, Endres M, Galla HJ, Steinmetz H, Busse R, NeumannHaefelin T, Brandes RP (2007) NADPH oxidase plays a central role in blood-brain barrier damage in experimental stroke. Stroke 38:30003006.

Kang JS, Lee BJ, Ahn B, Kim DJ, Nam SY, Yun YW, Nam KT, Choi M, Kim HS, Jang DD, Lee YS, Yang KH (2003) Expression of estrogen receptor alpha and beta in the uterus and vagina of immature rats treated with 17-ethinyl estradiol. J Vet Med Sci 65:1293-1297.

Kwon T, Kwon DY, Chun J, Kim JH, Kang SS (2000) Akt protein kinase inhibits Rac1-GTP binding through phosphorylation at serine 71 of Rac1. J Biol Chem 275:423-428.

Li C, Brake WG, Romeo RD, Dunlop JC, Gordon M, Buzescu R, Magarinos AM, Allen PB, Greengard P, Luine V, McEwen BS (2004) Estrogen alters hippocampal dendritic spine shape and enhances synaptic protein immunoreactivity and spatial memory in female mice. Proc Natl Acad Sci U S A 101:2185-2190.

Liang YQ, Akishita M, Kim S, Ako J, Hashimoto M, Iijima K, Ohike Y, Watanabe T, Sudoh N, Toba K, Yoshizumi M, Ouchi Y (2002) Estrogen receptor beta is involved in the anorectic action of estrogen. Int J Obes Relat Metab Disord 26:1103-1109.

Maki PM (2006) Hormone therapy and cognitive function: is there a critical period for benefit? Neuroscience 138:1027-1030.

Mattson MP, Culmsee C, Yu ZF (2000) Apoptotic and antiapoptotic mechanisms in stroke. Cell Tissue Res 301:173-187.

Medlock KL, Lyttle CR, Kelepouris N, Newman ED, Sheehan DM (1991) Estradiol down-regulation of the rat uterine estrogen receptor. Proc Soc Exp Biol Med 196:293-300.

Miller NR, Jover T, Cohen HW, Zukin RS, Etgen AM (2005) Estrogen can act via estrogen receptor alpha and beta to protect hippocampal neurons against global ischemia-induced cell death. Endocrinology 146:30703079.

Morissette M, Al Sweidi S, Callier S, Di Paolo T (2008) Estrogen and SERM neuroprotection in animal models of Parkinson's disease. Mol Cell Endocrinol 290:60-69.

Muranyi M, Li PA (2006) Hyperglycemia increases superoxide production in the CA1 pyramidal neurons after global cerebral ischemia. Neurosci Lett 393:119-121.

Murphy SJ, McCullough LD, Smith JM (2004) Stroke in the female: role of biological sex and estrogen. ILAR J 45:147-159.

Nephew KP, Long X, Osborne E, Burke KA, Ahluwalia A, Bigsby RM (2000) Effect of estradiol on estrogen receptor expression in rat uterine cell types. Biol Reprod 62:168-177.

Niewada M, Kobayashi A, Sandercock PA, Kamiñski B, Członkowska A (2005) Influence of gender on baseline features and clinical outcomes among 17,370 patients with confirmed ischaemic stroke in the international stroke trial. Neuroepidemiology 24:123-128.

Park L, Zhou P, Pitstick R, Capone C, Anrather J, Norris EH, Younkin L, Younkin S, Carlson G, McEwen BS, Iadecola C (2008) Nox2-derived radicals contribute to neurovascular and behavioral dysfunction in mice overexpressing the amyloid precursor protein. Proc Natl Acad Sci U S A 105:1347-1352.

Peters O, Back T, Lindauer U, Busch C, Megow D, Dreier J, Dirnagl U (1998) Increased formation of reactive oxygen species after permanent and reversible middle cerebral artery occlusion in the rat. J Cereb Blood Flow Metab 18:196-205.

Pillai SB, Jones JM, Koos RD (2002) Treatment of rats with 17beta-estradiol or relaxin rapidly inhibits uterine estrogen receptor betal and beta 2 messenger ribonucleic acid levels. Biol Reprod 67:1919-1926.

Pinna C, Cignarella A, Sanvito P, Pelosi V, Bolego C (2008) Prolonged ovarian hormone deprivation impairs the protective vascular actions of estrogen receptor alpha agonists. Hypertension 51:1210-1217.

Pulsinelli WA, Brierley JB (1979) A new model of bilateral hemispheric ischemia in the unanesthetized rat. Stroke 10:267-272.

Pulsinelli WA, Buchan AM (1988) The four-vessel occlusion rat model: method for complete occlusion of vertebral arteries and control of collateral circulation. Stroke 19:913-914.

Rey FE, Cifuentes ME, Kiarash A, Quinn MT, Pagano PJ (2001) Novel competitive inhibitor of $\mathrm{NAD}(\mathrm{P}) \mathrm{H}$ oxidase assembly attenuates vascular $\mathrm{O}(2)(-)$ and systolic blood pressure in mice. Circ Res 89:408-414.

Rocca WA, Bower JH, Maraganore DM, Ahlskog JE, Grossardt BR, de Andrade M, Melton LJ 3rd (2007) Increased risk of cognitive impairment or dementia in women who underwent oophorectomy before menopause. Neurology 69:1074-1083.

Rocca WA, Grossardt BR, Maraganore DM (2008) The long-term effects of oophorectomy on cognitive and motor aging are age dependent. Neurodegener Dis 5:257-260.

Roquer J, Campello AR, Gomis M (2003) Sex differences in first-ever acute stroke. Stroke 34:1581-1585.

Sandstrom NJ, Williams CL (2001) Memory retention is modulated by acute estradiol and progesterone replacement. Behav Neurosci 115:384-393.

Serrano F, Kolluri NS, Wientjes FB, Card JP, Klann E (2003) NADPH oxidase immunoreactivity in the mouse brain. Brain Res 988:193-198.

Sherwin BB (2003) Estrogen and cognitive functioning in women. Endocr Rev 24:133-151.

Sherwin BB (2007a) The critical period hypothesis: can it explain discrepancies in the oestrogen-cognition literature? J Neuroendocrinol 19:77-81.

Sherwin BB (2007b) The clinical relevance of the relationship between estrogen and cognition in women. J Steroid Biochem Mol Biol 106:151-156.

Sherwin BB, Henry JF (2008) Brain aging modulates the neuroprotective effects of estrogen on selective aspects of cognition in women: a critical review. Front Neuroendocrinol 29:88-113.

Shumaker SA, Legault C, Rapp SR, Thal L, Wallace RB, Ockene JK, Hendrix SL, Jones BN 3rd, Assaf AR, Jackson RD, Kotchen JM, WassertheilSmoller S, Wactawski-Wende J (2003) Estrogen plus progestin and the incidence of dementia and mild cognitive impairment in postmenopausal women: the Women's Health Initiative Memory Study: a randomized controlled trial. JAMA 289:2651-2662.

Shuster LT, Gostout BS, Grossardt BR, Rocca WA (2008) Prophylactic oo- 
phorectomy in premenopausal women and long-term health. Menopause Int 14:111-116.

Simoncini T, Hafezi-Moghadam A, Brazil DP, Ley K, Chin WW, Liao JK (2000) Interaction of oestrogen receptor with the regulatory subunit of phosphatidylinositol-3-OH kinase. Nature 407:538-541.

Simpkins JW, Rajakumar G, Zhang YQ, Simpkins CE, Greenwald D, Yu CJ, Bodor N, Day AL (1997) Estrogens may reduce mortality and ischemic damage caused by middle cerebral artery occlusion in the female rat. J Neurosurg 87:724-730.

Spencer JL, Waters EM, Romeo RD, Wood GE, Milner TA, McEwen BS (2008) Uncovering the mechanisms of estrogen effects on hippocampal function. Front Neuroendocrinol 29:219-237.

Sugawara T, Kinouchi H, Oda M, Shoji H, Omae T, Mizoi K (2005) Candesartan reduces superoxide production after global cerebral ischemia. Neuroreport 16:325-328.

Suzuki S, Brown CM, Dela Cruz CD, Yang E, Bridwell DA, Wise PM (2007) Timing of estrogen therapy after ovariectomy dictates the efficacy of its neuroprotective and antiinflammatory actions. Proc Natl Acad Sci U S A 104:6013-6018.

Tang XN, Cairns B, Cairns N, Yenari MA (2008) Apocynin improves outcome in experimental stroke with a narrow dose range. Neuroscience 154:556-562.

Toung TJ, Traystman RJ, Hurn PD (1998) Estrogen-mediated neuroprotection after experimental stroke in male rats. Stroke 29:1666-1670.
Wakade C, Khan MM, De Sevilla LM, Zhang QG, Mahesh VB, Brann DW (2008) Tamoxifen neuroprotection in cerebral ischemia involves attenuation of kinase activation and superoxide production and potentiation of mitochondrial superoxide dismutase. Endocrinology 149:367-379.

Walf AA, Ciriza I, Garcia-Segura LM, Frye CA (2008) Antisense oligodeoxynucleotides for estrogen receptor-beta and alpha attenuate estradiol's modulation of affective and sexual behavior, respectively. Neuropsychopharmacology 33:431-440.

Wassertheil-Smoller S, Hendrix SL, Limacher M, Heiss G, Kooperberg C, Baird A, Kotchen T, Curb JD, Black H, Rossouw JE, Aragaki A, Safford M, Stein E, Laowattana S, Mysiw WJ (2003) Effect of estrogen plus progestin on stroke in postmenopausal women: the Women's Health Initiative: a randomized trial. JAMA 289:2673-2684.

Zhang QG, Tian H, Li HC, Zhang GY (2006a) Antioxidant N-acetylcysteine inhibits the activation of JNK3 mediated by the GluR6-PSD95-MLK3 signaling module during cerebral ischemia in rat hippocampus. Neurosci Lett 408:159-164.

Zhang QG, Wang XT, Han D, Yin XH, Zhang GY, Xu TL (2006b) Akt inhibits MLK3/JNK3 signaling by inactivating Racl: a protective mechanism against ischemic brain injury. J Neurochem 98:1886-1898.

Zhang QG, Wang R, Khan M, Mahesh V, Brann DW (2008) Role of Dickkopf- 1 , an antagonist of the Wnt $/ \beta$-catenin signaling pathway, in estrogen-induced neuroprotection and attenuation of tau phosphorylation. J Neurosci 28:8430-8441. 